\title{
Hyaluronan-Binding Protein Involved in Hyaluronan Depolymerization Controls Endochondral Ossification through Hyaluronan Metabolism
}

\author{
Masayuki Shimoda, ${ }^{*}$ Hiroyuki Yoshida, ${ }^{\dagger}$ Sakiko Mizuno, ${ }^{\ddagger}$ Toru Hirozane ${ }^{\ddagger}$ Keisuke Horiuchi, ${ }^{\ddagger}$ Yuta Yoshino, ${ }^{\S}$ Hideaki Hara, \\ Yae Kanai, ${ }^{*}$ Shintaro Inoue, "Muneaki Ishijima, and Yasunori Okada****
}

From the Departments of Pathology* and Orthopaedic Surgery, ${ }^{\ddagger}$ Keio University School of Medicine, Tokyo, Japan; Biological Science Research, ${ }^{\dagger}$ Kao Corporation, Kanagawa, Japan; Molecular Pharmacology, ${ }^{\S}$ Department of Biofunctional Evaluation, and Cosmetic Health Science, ${ }^{\boldsymbol{\pi}}$ Gifu Pharmaceutical University, Gifu, Japan; and the Departments of Orthopaedic Surgery and Pathophysiology for Locomotive and Neoplastic Diseases, ** Juntendo University Graduate School of Medicine, Tokyo, Japan

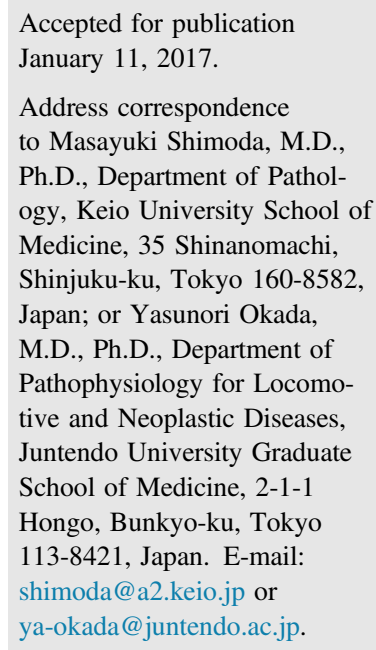

\begin{abstract}
Hyaluronan (HA) plays an important role in the development and maintenance of tissues, and its degradation is implicated in many pathologic conditions. We recently reported that HA-binding protein involved in HA depolymerization (CEMIP; alias HYBID/KIAA1199) is a key molecule in HA depolymerization, but its developmental and pathologic functions remain elusive. We generated Hybid-deficient mice using the Cre/locus of crossover in P1 (loxP) system and analyzed their phenotypes. Hybiddeficient mice were viable and fertile, but their adult long bones were shorter than those of wildtype animals. Hybid-deficient mice showed lengthening of hypertrophic zone in the growth plate until 4 weeks after birth. There were fewer capillaries and osteoclasts at the chondroosseous junction in the Hybid-deficient mice compared with the wild-type mice. In situ hybridization demonstrated that Hybid was expressed by hypertrophic chondrocytes at the chondroosseous junction. Cultured primary chondrocytes expressed higher levels of Hybid than did osteoblasts or osteoclasts, and the Hybid expression in the chondrocytes was up-regulated after maturation to hypertrophic chondrocytes. High-molecular-weight HA was accumulated in the lengthened hypertrophic zone in Hybid-deficient mice. In addition, high-molecular-weight HA significantly reduced cell growth and tube formation in vascular endothelial growth factor-stimulated or -nonstimulated endothelial cells. HA metabolism by HYBID is involved in endochondral ossification during postnatal development by modulation of angiogenesis and osteoclast recruitment at the chondroosseous junction. (Am J Pathol 2017, 187: 1162-1176; http://dx.doi.org/10.1016/j.ajpath.2017.01.005)
\end{abstract}

Hyaluronan (HA), a high-molecular-weight, nonsulfated glycosaminoglycan, is a major component of the extracellular matrix (ECM) present in many tissues, including the skin, cartilage, and other connective tissues, and provides structural and functional integrity to the organs. ${ }^{1}$ An HA-rich, hydrated ECM facilitates cellular movement and proliferation, which are essential not only for organogenesis during development but also for regeneration and remodeling of tissues during wound healing. ${ }^{2}$ Excessive degradation of HA has been observed in various pathologic conditions, including inflammation and cancers. ${ }^{3}$ HA levels in local tissues are thought to be controlled by HA synthases and hyaluronidases (HYAL). ${ }^{4}$ Of the six known HYALs in mammals, HYAL1 and -2 and cell surface HA receptor CD44 have been reported to play key roles in HA degradation. $^{2}$ High-molecular-weight $\mathrm{HA}$ is tethered to cell

Supported by Japan Society for the Promotion of Science Grant-in-Aid for Scientific Research (JSPS KAKENHI) grants 16H05454 (Y.O.) and 16K08719 (M.S.); the Nakatomi Foundation, Sumitomo Foundation grant 151504; and a grant from the Yasuda Medical Foundation (M.S.).

Disclosures: H.Y. is an employee of Kao Corporation. H.Y. and S.I. are holders of the patent on HYBID/KIAA1199. Hyaluronan species were gifts from Chugai Pharmaceutical Co., Ltd., Tokyo, Japan. 
surfaces by CD44 concentrated in caveolin-rich lipid rafts and cleaved by HYAL2 into intermediate-size fragments. Then, the fragments are degraded into oligosaccharides by the lysosomal enzyme HYAL1 in coordination with other glycolytic lysosomal enzymes. On the other hand, we recently reported that HA-binding protein involved in HA depolymerization (CEMIP; alias HYBID/KIAA1199), ${ }^{5}$ plays a key role in HA degradation independent of the HYAL1 and HYAL2/CD44 systems. ${ }^{5,6}$ HYBID was first discovered as an inner-ear protein the genetic mutations of which were linked to nonsyndromic hearing loss. ${ }^{7}$ However, our studies have demonstrated that human HYBID is involved in endogenous HA degradation in human normal skin and synovial fibroblasts through specific binding with HA. ${ }^{5,6}$ We have also shown that similar processes are present with murine Hybid. ${ }^{8}$ HYBID contains a predicted 4083 bp open reading frame encoding a protein that is composed of four parallel $\beta$-helix repeat-1 domains, one eight conserved glycine residues domain, and two GG domains with seven predicted $\mathrm{N}$-glycosylation sites, and an N-terminal 30-amino acid portion corresponding to the signal sequence of HYBID is ascribed to its proper translocation and cellular HA-depolymerizing activity. ${ }^{9}$

The axial and appendicular skeletons are formed by endochondral ossification, a process that is initiated during embryogenesis by mesenchymal cell condensation and differentiation into chondrocytes. ${ }^{10}$ Endochondral ossification requires terminal differentiation, apoptosis of chondrocytes, and remodeling of the cartilage ECM, which are followed by vascular invasion and formation of trabecular bone. During these sequential processes, angiogenesis is a crucial step, ${ }^{11-13}$ and remodeling of the accumulated ECM in the hypertrophic zone is essential for vascular invasion. ${ }^{14-17}$ Since HA is one of the major ECM components in the hypertrophic zone in the growth plate, changes in turnover of $\mathrm{HA}$ are suspected to influence endochondral ossification. In fact, mice lacking the Has 2 gene exhibited defective chondrocyte condensation and maturation and abnormal joint formation, ${ }^{18}$ suggesting that HA synthesis is indispensable for long bone development. The HA-degradation system was also expected to affect endochondral ossification, but previous studies have shown that mice deficient in Hyal, such as Hyal1 and -2, exhibit no obvious abnormalities in long bone development. ${ }^{19-21}$ Therefore, the molecule(s) involved in HA degradation during endochondral ossification have not been identified, and whether HA catabolism is necessary for normal endochondral ossification is still an open question.

Human HYBID is highly expressed in rheumatoid or osteoarthritic synovium, ${ }^{5}$ cancer tissues such as carcinomas of the colorectum and stomach, ${ }^{22,23}$ and skin fibroblasts in patients with Werner syndrome, an adult-onset progeroid disease. ${ }^{22}$ Accumulating evidence indicates that increased lower-molecular-weight $\mathrm{HA}$ is a hallmark of various diseases, ${ }^{3}$ and a recent study in naked mole rats showing a link between resistance to cancer and extraordinarily highmolecular-weight HA accumulation shed light on the importance of HA catabolism in the context of carcinogenesis and cancer progression in vivo. ${ }^{24}$ These data prompted us to speculate that HYBID-mediated HA degradation is involved in the development of various human diseases. However, no tools to experimentally investigate the in vivo functions of this molecule under pathologic conditions have been provided.

Here, we generated global Hybid-deficient $\left(\mathrm{Hybid}^{-/-}\right.$) mice using the Cre/loxP (locus of crossover in P1) system and analyzed their phenotypes. These mice superficially exhibited no overt abnormalities but showed shorter long bones due to impaired endochondral ossification. The hypertrophic zone of the bones was temporally lengthened, and fewer capillaries and osteoclasts were present at the chondroosseous junction. High-molecular-weight HA was accumulated in the growth plates of the $\mathrm{Hybid}^{-1-}$ mice. We also provided the experimental data that high-molecularweight HA suppresses growth and tube formation in endothelial cells. These data suggest that HYBID-mediated HA metabolism is involved in turnover of the growth plate during postnatal development via promotion of angiogenesis and osteoclast recruitment at the chondroosseous junction. The $\mathrm{Hybid}^{-1-}$ mice will be useful tools for the examination of HA metabolism in vivo under various pathophysiological conditions.

\section{Materials and Methods}

\section{Generation of Hybid-Deficient Mice}

For the construction of the floxed Hybid-targeting vector, the first exon was flanked by two loxP sites and an FMRFamide-like neuropeptide recombination targetflanked neo cassette (Figure 1A). TT2 [(C57BL/6NCrlj $\times$ $\mathrm{CBA} / \mathrm{JNCrlj}$ )F1] embryonic stem cells harboring the targeted Hybid allele were identified by Southern blot analysis (data not shown). Chimeric mice were generated by C57BL/6 blastocyst injection and bred with C57BL/6 mice to generate heterozygous mice. The mice were crossed with transgenic mice expressing Cre recombinase gene under the control of CAG promoter (CAG-Cre) ${ }^{25}$ to generate mice heterozygous for the floxed Hybid allele (henceforth referred to as $\mathrm{Hybid}^{+-}$). Those mice were further mated to generate Hybid-null homozygous mice (henceforth referred to as Hybid $^{-1-}$ ). These Hybid $^{-1-}$ mice were backcrossed eight times into the C57BL/6 background. In experiments with Hybid $^{-1-}$ mice, age- and sex-matched wild-type (henceforth referred to as control mice) or littermate $\mathrm{Hybid}^{+/}$mice served as controls. The protocol of each animal experiment was approved by the Institutional Animal Care and Use Committee at Keio University School of Medicine (Tokyo, Japan).

\section{Primary Cell Cultures}

Primary mouse dermal fibroblasts were isolated by outgrowth from skin explants obtained from 2-week-old 
A

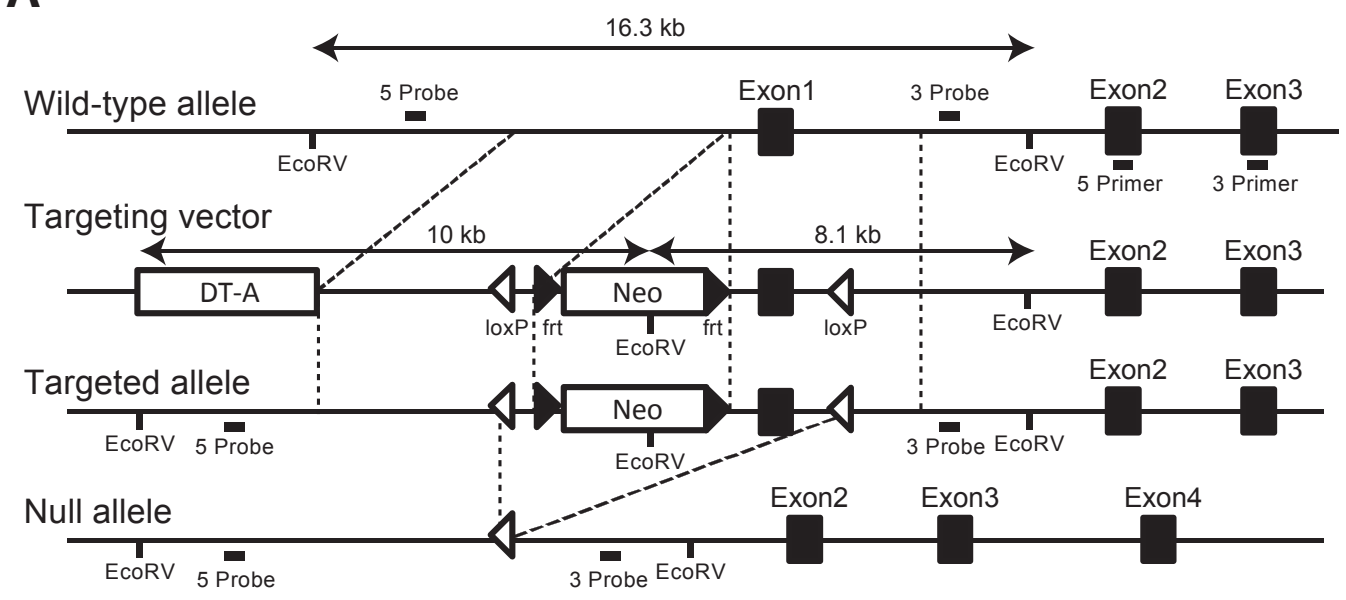

B

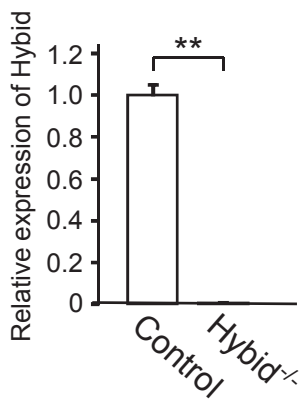

C

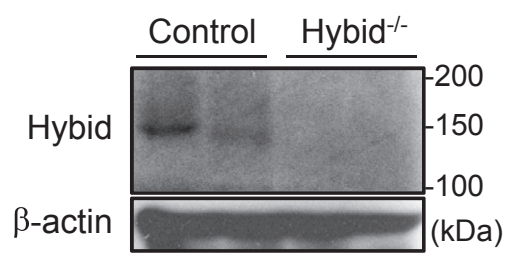

Figure 1 Generation of Hybid ${ }^{\text {flox/flox }}$ and Hybid ${ }^{-/-}$mice. A: Scheme for conditional targeting of the Hybid gene. Structures of the endogenous mouse locus (wild-type allele), the transgene targeting cassette (targeting vector), the targeted floxed allele resulting from homologous recombination (targeted allele), and the null allele resulting from Cre-mediated recombination (null allele) are depicted. White arrowheads indicate loxP (locus of crossover in P1) sites placed surrounding exon 1 and phosphoglycerate kinase (PKG)-neo cassette. Black arrowheads indicate FMRFamide-like neuropeptide recombination target sites. The positions of Southern blot probes ( $5^{\prime}$ and $3^{\prime}$ probes) and real-time quantitative PCR (qPCR) primers for Hybid ( $5^{\prime}$ and $3^{\prime}$ primers) are indicated by thick lines. B: Relative gene expression of Hybid by qPCR in mouse dermal fibroblasts from the control and $\mathrm{Hybid}^{-1-}$ mice at 2 weeks after birth. C: Immunoblot analysis of Hybid in mouse dermal fibroblasts from the control and $\mathrm{Hybid}^{-/-}$mice at 2 weeks after birth. $\beta$-Actin was used as a loading control. Data are expressed as means \pm SD. $n=3$ per group. ${ }^{*} P<0.01$. DT-A, diptheria toxin A.

mice as described before. ${ }^{26}$ Briefly, the skin from control or Hybid $^{-1-}$ mice was removed aseptically, minced with surgical blades, and subsequently cultured in Dulbecco's modified Eagle's medium (DMEM) (InvitroGen, Carlsbad, CA) containing $10 \%$ fetal bovine serum and antibiotics. Growing fibroblasts were further cultured for three passages before experimental use. For the culture of primary chondrocytes, cartilages isolated from neonatal mouse ribs were incubated in DMEM containing 0.3\% collagenase (Wako, Osaka, Japan) at $37^{\circ} \mathrm{C}$ for 5 hours. After the digestion, cell suspensions were collected by centrifugation at $250 \times g$ for 5 minutes. The resultant pellets were suspended in DMEM containing $10 \%$ fetal bovine serum. The primary chondrocytes were plated at a density of $1 \times 10^{4} \mathrm{cells} / \mathrm{cm}^{2}$ and then cultured at $37^{\circ} \mathrm{C}$ under $5 \% \mathrm{CO}_{2}$. They were also cultured for 4 weeks in chondrogenic differentiation medium, DMEM/Ham F12 (1:1) medium (InvitroGen) supplemented with $10 \mu \mathrm{g} / \mathrm{mL}$ human transferrin (SigmaAldrich, St. Louis, MO), $300 \mu \mathrm{mol} / \mathrm{L}$ sodium selenite (Sigma-Aldrich), and $10 \mu \mathrm{g} / \mathrm{mL}$ bovine insulin (Sigma-
Aldrich). Primary osteoblasts were harvested from the calvaria of newborn mice as described previously. ${ }^{27}$ For primary osteoclast culture, bone marrow-derived macrophages were prepared as previously described ${ }^{28}$ and used as osteoclast precursors. They were cultured in the presence of $50 \mathrm{ng} / \mathrm{mL}$ soluble receptor activator of NF- $\kappa \mathrm{B}$ ligand and $3.3 \times 10^{3} \mathrm{U} / \mathrm{mL}$ macrophage-colony stimulating factor for 5 days to induce osteoclastogenesis.

\section{Gene Expression Analysis}

Total RNA was extracted from freshly isolated mouse tissues and cultured cells by using Isogen (Nippon Gene, Tokyo, Japan) or RNeasy (Qiagen, Alameda, CA) and reverse-transcribed with ReverTra Ace reverse transcriptase (Toyobo Life Science, Tokyo, Japan) as recommended by the manufacturer. Real-time quantitative PCR was performed by an ABI 7000 cycler with SYBR Green Master Mix (InvitroGen). The PCR primers used for measuring gene expression of Hybid (Cemip), Hyall, Hyal2, $\alpha_{1}$ type X 
Table 1 Primer Sequences Used for Real-Time Quantitative PCR Analysis

\begin{tabular}{|c|c|}
\hline Gene name & Oligonucleotide sequence \\
\hline \multirow[t]{2}{*}{ Hybid (Cemip) } & Forward: 5'-СТССТGGCСААСТTCTCAGG-3' \\
\hline & Reverse: 5'-TGCCATGGCCAATGTGTACT-3' \\
\hline \multirow[t]{2}{*}{ Hyal1 } & Forward: 5'-TGCCCGTAATGCCCTACGT-3' \\
\hline & Reverse: 5'-GCTGTGCTCCAGTTCCTCCA-3' \\
\hline \multirow[t]{2}{*}{ Hyal2 } & Forward: 5'-CGAGGACTCACGGGACTGA-3' \\
\hline & Reverse: $5^{\prime}$-GGCACTCTCACCGATGGTAGA-3' \\
\hline \multirow[t]{2}{*}{ Col10a1 } & Forward: 5'-ACGCATCTCCCAGCACCAGAATC-3' \\
\hline & Reverse: 5'-GGGGCTAGCAAGTGGGCCCT-3' \\
\hline \multirow[t]{2}{*}{ Mmp13 } & Forward: 5'-ATGGTCCAGGCGATGAAGACCCC-3' \\
\hline & Reverse: 5'-GTGCAGGCGCCAGAAGAATCTGT-3' \\
\hline \multirow[t]{2}{*}{ Has1 } & Forward: 5'-TATGCTACCAAGTATACCTCG-3' \\
\hline & Reverse: 5'-TCTCGGAAGTAAGATTTGGAC-3' \\
\hline \multirow[t]{2}{*}{ Has2 } & Forward: 5'-CAAAAATGGGGTGGAAAGAG-3' \\
\hline & Reverse: $5^{\prime}$-ACAGATGAGGCAGGGTCAAG-3' \\
\hline \multirow[t]{2}{*}{ Actb } & Forward: 5'-AGGGAAATCGTGCGTGACAT-3' \\
\hline & Reverse: 5'-GAACCGCTCGTTGCCAATAG-3' \\
\hline
\end{tabular}

collagen (Col10a1), matrix metalloproteinase-13 (Mmp13), Hasl, Has2, and $\beta$-actin (Actb) are described in Table 1. Gene expression levels were determined in triplicate and normalized to the expression of Actb, which remained similar in the various groups.

\section{Western Blot Analysis}

Cultured cells were homogenized in $50 \mathrm{mmol} / \mathrm{L}$ Tris- $\mathrm{HCl}$, pH 7.4, $150 \mathrm{mmol} / \mathrm{L} \mathrm{NaCl}, 10 \mathrm{mmol} / \mathrm{L} \mathrm{CaCl}_{2}, 1 \% \mathrm{NP}-40$ (lysis buffer) containing complete proteinase inhibitors (Roche Diagnostics, Tokyo, Japan), $1 \mathrm{mmol} / \mathrm{L} \mathrm{Na}_{3} \mathrm{VO}_{4}$, and $10 \mathrm{mmol} / \mathrm{L} \mathrm{NaF}$, and homogenate supernatants were used for sodium dodecyl sulfate-polyacrylamide gel electrophoresis. ${ }^{29}$ Proteins were transferred to polyvinylidene difluoride membranes, and the membranes were incubated with polyclonal rabbit anti-Hybid antibody (catalog number SAB2105467; Sigma-Aldrich) recognizing parallel $\beta$-helix repeat 1 domain of Hybid or mouse anti- $\beta$-actin (catalog number A5441; Sigma-Aldrich). Subsequently, the membranes were incubated with secondary antibodies, visualized by chemiluminescence, and quantified by image analysis.

\section{X-Ray Analysis}

$\mathrm{X}$-ray images of disarticulated limbs were imported and the lengths of the bones measured using Photoshop Creative Suite software version 4 (Adobe, Tokyo, Japan). The longest distances from the proximal to the distal joint of tibiae and femurs were measured.

\section{Whole-Mount Alcian Blue and Alizarin Red Staining}

Alcian Blue and Alizarin Red staining was performed using a modified version of the McLeod method on ethanol-fixed samples. ${ }^{30}$ Briefly, sacrificed newborn mice were skinned, eviscerated, and fixed in 95\% ethanol for 10 days.
Specimens were then stained with Alcian Blue, followed by clearing of the skeleton with potassium hydroxide and staining of the bones with Alizarin Red.

\section{Histologic Staining}

Tissue samples were fixed at $4{ }^{\circ} \mathrm{C}$ in $4 \%$ paraformaldehyde. After removal of paraformaldehyde, they were decalcified with $10 \%$ EDTA in $0.1 \mathrm{~mol} / \mathrm{L}$ Tris-HCl buffer, $\mathrm{pH} 7.4$, for 6 to 14 days, depending on the age of the mice. They were embedded in paraffin, sectioned, and then stained with hematoxylin and eosin and Alcian Blue according to standard protocols.

\section{5'-Bromo-2'-Deoxyuridine Incorporation Assay}

Cells in S phase were labeled by i.p. administration of $30 \mu \mathrm{g} / \mathrm{g}$ body 5'-bromo-2'-deoxyuridine (BD Pharmingen, San Jose, $\mathrm{CA}$ ) in phosphate-buffered saline. Bone tissues were excised at 4 hours after injection and fixed in $4 \%$ paraformaldehyde. Paraffin sections of the bone were immunostained with anti-5'-bromo-2'-deoxyuridine antibody (Bu20a; Dako Cytomation, Tokyo, Japan) as described in Immunohistochemistry Analysis, and they were counterstained with hematoxylin. The proliferation rate of the cells in proliferating zone of the growth plate was quantified by a count of the number of the cells in five different fields at a magnification of $\times 400$.

\section{Apoptosis and TRAP Staining}

For detection of apoptosis, terminal deoxytransferasemediated deoxy uridine nick end-labeling assay was performed using the ApopTag peroxidase in situ apoptosis detection kit (Chemicon International, Billerica, MA) according to the manufacturer's instructions. Tartrateresistant acid phosphatase (TRAP) staining was performed on deparaffinized and rehydrated sections using L-(+)-tartaric acid and the New Fuchsin alkaline phosphatase substrate kit (Nichirei Biosciences, Tokyo, Japan). These sections were counterstained with methyl green.

\section{Staining of HA}

HA localization was determined using the biotinylated HA-binding protein by modification of the technique described previously. ${ }^{31}$ Briefly, after blocking of endogenous peroxidase activity, the sections were incubated with $2 \mu \mathrm{g} / \mathrm{mL}$ biotinylated HA-binding protein (Hokudo, Sapporo, Japan) in phosphate-buffered saline containing $10 \%$ fetal bovine serum for 1 hour. After washing in phosphate-buffered saline, the slides were incubated with streptavidin horseradish peroxidase (BD Pharmingen) for 1 hour, washed in phosphate-buffered saline, and incubated in a solution of 3,3'-diaminobenzidine tetrahydrochloride (Sigma-Aldrich). They were counterstained with hematoxylin. Control slides were pre-incubated with 200 tenfold reduction units/mL Streptomyces hyaluronidase 
(Seikagaku, Tokyo, Japan), a selective carbohydratedigesting enzyme, in $100 \mathrm{mmol} / \mathrm{L}$ sodium acetate at $60^{\circ} \mathrm{C}$ for 2 hours. This enzyme degrades HA and therefore serves as a control, showing the specificity of the method.

\section{Immunohistochemistry Analysis}

Paraformaldehyde-fixed paraffin sections were subjected to immunohistochemistry analysis for Mmp-9 using polyclonal goat anti-Mmp-9 antibody (R\&D Systems, Minneapolis, MN). They were followed by reactions with ImmPRESS anti-mouse Ig kit secondary antibody (Vector Laboratories, Burlingame, CA). Immunostaining for CD31 was performed using the multipurpose tissue-processing and paraffinembedding (AMeX) method. ${ }^{32}$ Briefly, tissues were fixed in acetone at $-20^{\circ} \mathrm{C}$ overnight, then cleared in methyl benzoate and xylene, consecutively, and embedded in ordinary paraffin at $58^{\circ} \mathrm{C}$ to $60^{\circ} \mathrm{C}$. Paraffin sections were subjected to immunohistochemistry analysis for CD31 with rat anti-CD31 monoclonal antibody (catalog number MEC13.3; BD Biosciences, San Jose, CA), followed by reactions with anti-rat fragment antigen-binding fragments conjugated to horseradish peroxidase-labeled amino acid polymer (Nichirei Biosciences). Color was developed with diaminobenzidine tetrahydrochloride. After immunohistochemistry analysis, the sections were counterstained with hematoxylin. For assessment of osteoclasts at the chondroosseous junction of the growth plate, numbers of TRAP- or Mmp-9-positive cells were counted at $\times 400$ magnification by an investigator blinded to the samples examined (M.S.).

\section{In Situ Hybridization}

Paraffin-embedded sections of bone tissues were used for in situ hybridization. The sections were deparaffinized and then probed for Col10a1, Mmp-13, vascular endothelial growth factor (VEGF), and Hybid transcripts using an RNAscope 2.0 HD reagent kit (Probe-Mm-Col10a1, catalog number 426181; Probe-Mm-Mmp13, catalog number 427601; ProbeMm-Vegfa-ver2, catalog number 412261; and Probe-MmCemip, catalog number 43823; Advanced Cell Diagnostics, Newark, CA) as instructed by the manufacturer. The sections were counterstained with Mayer hematoxylin.

\section{Measurement of HA Content in Cartilage Tissues}

HA was extracted from the cartilage tissues according to the methods previously described. ${ }^{33}$ Briefly, the cartilage tissues were freeze-dried and incubated in $50 \mathrm{mmol} / \mathrm{L}$ Tris$\mathrm{HCl}$ buffer, $0.5 \%$ SDS, and $100 \mathrm{mmol} / \mathrm{L}$ EDTA containing $0.2 \mathrm{mg} / \mathrm{mL}$ of proteinase $\mathrm{K}$ (Sigma-Aldrich) at $55^{\circ} \mathrm{C}$ for 5 hours. HA was purified with phenol/chloroform. The HA content was determined using the QnE HA enzyme-linked immunosorbent assay kit (Biotech Trading Partners, LLC, Encinitas, CA) according to the manufacturer's protocol.

\section{Determination of HA Molecular Weight Distribution}

Molecular weight of purified HA samples of $0.5 \mu \mathrm{g}$ was determined by high-performance liquid chromatography using a Shodex OHpak SB-807 HQ column $(0.8 \times 30 \mathrm{~cm}$; Showa Denko, Tokyo, Japan) and $0.2 \mathrm{~mol} / \mathrm{L} \mathrm{NaCl}$ in distilled water. The flow rate was $0.5 \mathrm{~mL} /$ minute. Fractions of $0.5 \mathrm{~mL}$ were collected and HA content was measured by the QnE HA enzyme-linked immunosorbent assay according to the manufacturer's protocol. The column was calibrated with HA species: NaHA-H2 (2500 kDa), M2 (1000 $\mathrm{kDa})$, and $\mathrm{L} 2(150 \mathrm{kDa})$, all of which were purchased from PG Research (Tokyo, Japan).

\section{Endothelial Cell Growth and Tube Formation Assays}

Human umbilical vein endothelial cells were purchased from Lonza (Cologne, Germany) and cultured in endothelial basal medium-2 (Lonza) supplemented with EGM-2 SingleQuots (Lonza). For assessment of cell growth, xCELLigence (Acea Biosciences, San Diego, CA) cell index impedance measurements were performed according to the instructions of the supplier. ${ }^{34}$ Briefly, human umbilical vein endothelial cells were trypsinized and suspended in endothelial basal medium2 supplemented with $2 \%$ fetal bovine serum and antibiotics. After seeding $2 \times 10^{3}$ cells in each well of the E-plate 96 (Acea) in the absence or presence of $50 \mathrm{ng} / \mathrm{mL}$ recombinant human VEGF (R\&D Systems) or mixture of $50 \mathrm{ng} / \mathrm{mL}$ VEGF and HA species of different molecular weights, $2.5 \mathrm{mg} / \mathrm{mL}$ $2700 \mathrm{kDa}$ or $250 \mu \mathrm{g} / \mathrm{mL} 2.4 \mathrm{kDa}$ (gifts from Chugai Pharmaceutical Co., Ltd., Tokyo, Japan), cell index impedance was monitored after a 48-hour culture by the xCELLigence system. Endothelial cell tube formation assay using human umbilical vein endothelial cells on a basement membrane substratum was performed as described previously. ${ }^{35}$ Briefly, Cultrex basement membrane extract (Trevigen, Gaithersburg, MD) was dispensed to 96-well culture plates and incubated at $37^{\circ} \mathrm{C}$ for 1 hour to allow the basement membrane extract to gel. Human umbilical vein endothelial cells were trypsinized and plated on the basement membrane extract gel at a density of 15,000 cells/well. They were cultured in endothelial basal medium- 2 in the absence or presence of $50 \mathrm{ng} / \mathrm{mL}$ VEGF or a mixture of $50 \mathrm{ng} / \mathrm{mL}$ VEGF and HA species $(2.5 \mathrm{mg} / \mathrm{mL}$ for $2700-\mathrm{kDa} \mathrm{HA}$ and $250 \mu \mathrm{g} / \mathrm{mL}$ for $2.4-\mathrm{kDa} \mathrm{HA}){ }^{36}$ After 6 hours of culture, images of each well were obtained, and the tubular lengths (in $\mathrm{mm} / \mathrm{mm}^{2}$ ) of the cells were measured in five different areas by using ImageJ software version $1.50 \mathrm{~g}$ (NIH, Bethesda, MD; http://imagej.nih.gov/ij) as described previously. ${ }^{37}$

\section{Statistical Analysis}

Data are reported as means $\pm \mathrm{SD}$. The significance of the differences between the two independent groups was determined by the two-sided $t$-test. The significance of differences among more than three groups was determined 
Table 2 Distribution of Offspring from Hybid ${ }^{+/-} \times \mathrm{Hybid}^{+/-}$or $\mathrm{Hybid}^{+/-} \times \mathrm{Hybid}^{-/-}$Mating

\begin{tabular}{|c|c|c|c|c|}
\hline Mating & Total, $n(\%)$ & $+/+, n(\%)$ & $+/-, n(\%)$ & $-/-, n(\%)$ \\
\hline \multirow[t]{2}{*}{$\mathrm{Hybid}^{+/-} \times \mathrm{Hybid}^{+/-}$} & $133(100)$ & $81(60.9)$ & $49(36.8)$ & $3(2.3)$ \\
\hline & Expected mendelian ratios & $33.25(25.0)$ & $66.5(50.0)$ & $33.25(25.0)$ \\
\hline \multirow[t]{2}{*}{$\mathrm{Hybid}^{+/-} \times \mathrm{Hybid}^{-/-}$} & $114(100)$ & 0 & $49(43.0)$ & $65(57.0)$ \\
\hline & Expected mendelian ratios & 0 & $57(50.0)$ & $57(50.0)$ \\
\hline
\end{tabular}

by one-way analysis of variance followed by Bonferroni post hoc testing. $P$ values of $<0.05$ were considered significant.

\section{Results}

\section{Global Deletion of HYBID Results in Shorter Long Bones}

Mice containing a floxed Hybid allele were crossed with CAG-Cre mice to generate $\mathrm{Hybid}^{+/-}$animals that were then bred to produce $\mathrm{Hybid}^{-1-}$ mice (Figure 1A). Removal of floxed Hybid was confirmed by PCR and Southern blot analysis (data not shown), and the lack of Hybid mRNA and protein in primary dermal fibroblasts was corroborated by real-time quantitative PCR and Western blot analysis, respectively (Figure 1, B and C). Offspring of $\mathrm{Hybid}^{+-}$ mouse crosses were not born in the expected mendelian ratios, although the reasons for the abnormal inheritance are currently unknown. However, progeny were obtained by crosses of $\mathrm{Hybid}^{-1-}$ and $\mathrm{Hybid}^{+/-}$mice in the mendelian ratios (Table 2). Established Hybid ${ }^{-1-}$ mice were viable and fertile. Because of the limited number of $\mathrm{Hybid}^{-1-}$ mice from the offspring of $\mathrm{Hybid}^{+-}$mouse crosses, we compared $\mathrm{Hybid}^{-/-}$mice from the offspring of $\mathrm{Hybid}^{-/-}$ mice with age- and sex-matched control mice from the offspring of $\mathrm{Hybid}^{+/+}$mice obtained by $\mathrm{Hybid}^{+/-}$mouse crosses for detailed analyses. Hybid ${ }^{-1-}$ mice exhibited no growth retardation or overt skeletal defects (Figure 2, $\mathrm{A}-\mathrm{C}$ ). However, we found that length of the long bones was approximately $5 \%$ shorter in $\mathrm{Hybid}^{-1-}$ mice compared with control mice at 8 weeks of age (Figure 2, D and E). Gene expression analysis in various organs of control mice at 1 week after birth showed that the bone (the whole tibia) and the brain (the cerebrum and cerebellum) expressed high levels of Hybid mRNA, whereas the expression in the liver or thymus was almost negligible (Figure 2F).

\section{Hybid $^{-/-}$Mice Exhibit Elongation of Growth Plate during Development}

Endochondral ossification in the growth plate is involved in the longitudinal growth of the long bones. ${ }^{10}$ Thus, we tested whether growth plate of the long bones in $\mathrm{Hybid}^{-/}$mice has developmental abnormality, and found that hypertrophic zone in the growth plate was lengthened in $\mathrm{Hybid}^{-/-}$mice at 2 weeks of age compared with that in control mice (Figure 3, A and B). The lengthened hypertrophic zone in the $\mathrm{Hybid}^{-1-}$ mice was positively stained with Alcian Blue, and the hypertrophic chondrocytes expressed Col10a1 (Figure 3C). The expression of Mmp-13 was positive at the chondroosseous junction in the growth plate (Figure 3C). This phenotype of lengthening of the hypertrophic zone was transient, since the difference in the length of the hypertrophic zone was most conspicuous at 2 weeks of age and less obvious after 4 weeks (Figure 3, D and E). In addition, the hypertrophic zone was lengthened significantly more in Hybid $^{-/-}$mice than in their Hybid $^{+/-}$littermates (Figure 3F). These data suggest that deletion of the Hybid gene delays, but does not disrupt, endochondral ossification in the growth plate. We then examined proliferation rate of the cells in the proliferating zone by $5^{\prime}$-bromo-2'deoxyuridine labeling and found that the difference in the numbers of $5^{\prime}$-bromo- $2^{\prime}$-deoxyuridine-positive cells between control and $\mathrm{Hybid}^{-1-}$ mice was not significant (Figure 4A). Terminal deoxytransferase-mediated deoxy uridine nick end-labeling assay showed no obvious difference in the numbers of apoptotic cells at the chondroosseous junction between control and $\mathrm{Hybid}^{-1-}$ mice (Figure 4B). These results demonstrate that in the endochondral bones of Hybid $^{-1-}$ mice, chondrocytes proliferate and differentiate normally, but that they accumulate in the terminally differentiated hypertrophic state.

\section{Hybid $^{-/-}$Mice Have Fewer Osteoclasts and Blood Vessels at the Chondroosseous Junction during Development}

Resorption of calcified cartilage ECM and concurrent vascular invasion in the hypertrophic zone of the growth plate are an essential process of endochondral ossification. ${ }^{38}$ Since impairment of this process may be involved in the accumulation of hypertrophic chondrocytes in the Hybid ${ }^{-/-}$mouse growth plate, we evaluated the number and distribution of TRAP-positive osteoclasts in the developing bone. As expected, there were significantly fewer TRAP-positive osteoclasts at the chondroosseous junction in the $\mathrm{Hybid}^{-/-}$ mice than in the control mice (Figure 5A). Immunostaining of Mmp-9, an Mmp that is highly expressed by osteoclasts, showed localization to osteoclasts at the chondroosseous junction in the growth plate, confirming the data from TRAP staining (Figure 5B). Vascular density, determined by a count of CD31 immunostaining-positive endothelial cells at the chondroosseous junction, was significantly decreased in the Hybid $^{-/-}$mice compared with that in the control mice 

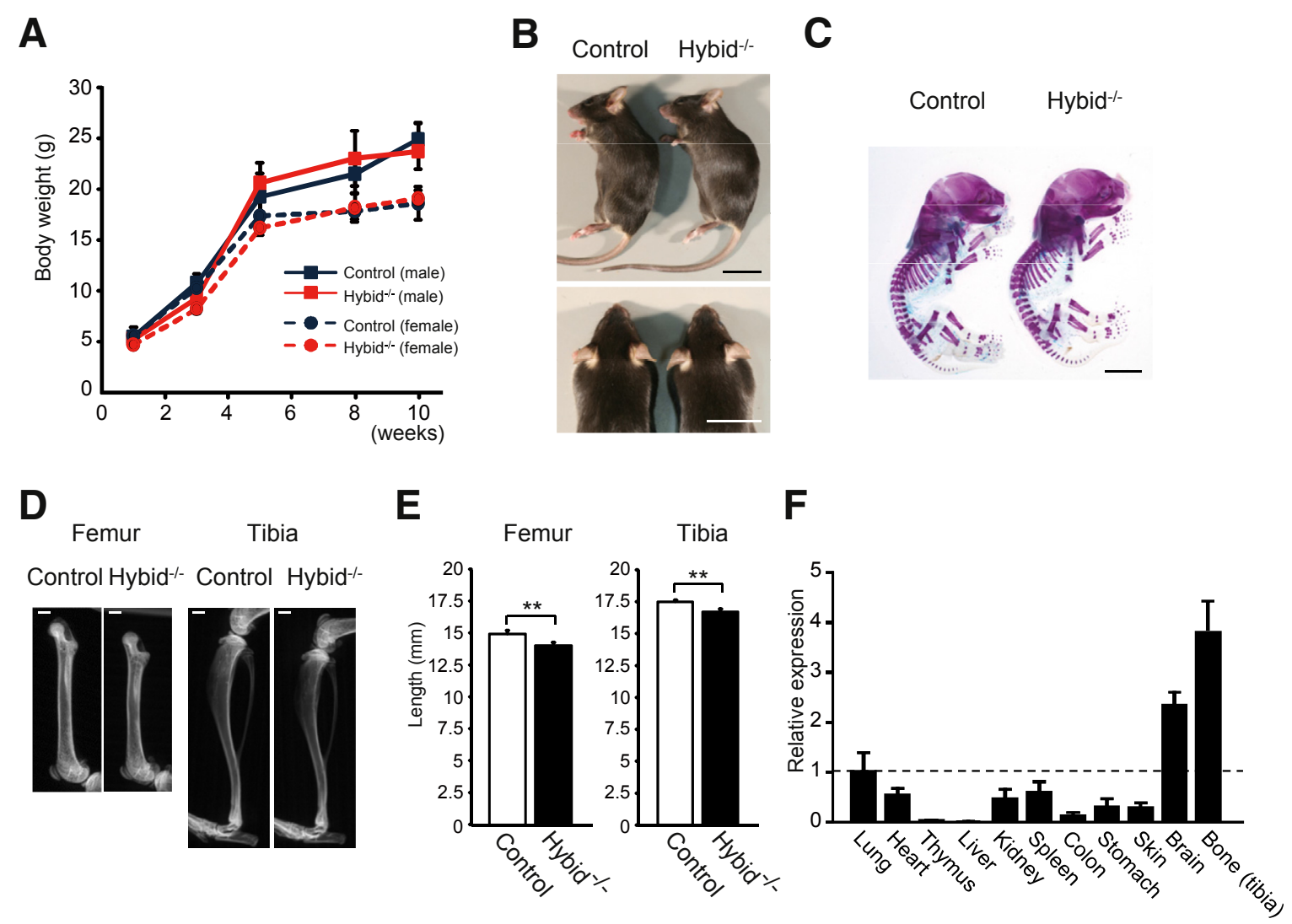

Figure 2 Global inactivation of HYBID results in shorter long bones. A: Body weight change in male and female Hybid ${ }^{-/-}$and control mice. B: Macroscopic appearance of the $\mathrm{Hybid}^{-1-}$ and control mice at 8 weeks after birth. C: Representative image of whole-mount bone and cartilage staining in newborn control and $\mathrm{Hybid}^{-/-}$mice. D: Radiographs of the lower limbs in 8-week-old Hybid ${ }^{-/-}$and control mice. E: Comparison of lengths of the femur and tibia between 8-week-old $\mathrm{Hybid}^{-1-}$ and control mice. F: Relative expression of Hybid in various organs from 1-week-old control mice. Dotted line indicates the expression level in the lung. Data are expressed as means \pm SD. $n=3$ to $7(\mathbf{A}) ; n=4\left(\mathbf{E}\right.$, Hybid $\left.^{-/}\right) ; n=5$ (E, control); $n=3$ to $4(\mathbf{F})$. ${ }^{* \star} P<0.01$. Scale bars: $2 \mathrm{~cm}$ (B); $5 \mathrm{~mm}($ C); $1 \mathrm{~mm}(\mathbf{D})$.

(Figure 5C). VEGF, which acts as an angiogenic factor at the chondroosseous junction, ${ }^{10}$ is a marker of the terminal rows of the hypertrophic chondrocyte zone. By in situ hybridization analysis, we showed that VEGF was expressed mainly by hypertrophic chondrocytes in the growth plate, and that the percentage of VEGF-positive cells in total cells was not changed between the $\mathrm{Hybid}^{-1-}$ mice and the control mice (Figure 5D). This finding indicates that impaired angiogenesis in $\mathrm{Hybid}^{-1-}$ mice is caused by a mechanism other than decreased VEGF production.

\section{Terminally Differentiated Chondrocytes Express HYBID}

To identify HYBID-expressing cells in the long bones, we performed in situ hybridization with the bone tissues from control mice and found that the expression of Hybid was localized predominantly to the cells at the chondroosseous junction adjacent to the hypertrophic zone, in which Col10a1 was strongly expressed by hypertrophic chondrocytes (Figure 6A). Mmp-13 was also expressed by the cells at the chondroosseous junction, showing an expression pattern similar to that of Hybid (Figure 6A). Although TRAP staining-positive osteoclasts were occasionally present at the chondroosseous junction, they appeared to be different from the cells expressing Hybid or Mmp-13 (Figure 6A). These data suggest that most of the HYBIDexpressing cells are terminally differentiated chondrocytes, but not osteoclasts. To confirm these histologic data, we analyzed Hybid expression in primary mouse cells by realtime quantitative PCR and found that the expression level was significantly higher in chondrocytes isolated from the control long bones than in osteoblasts or osteoclasts (Figure 6B). When primary chondrocytes were cultured in the chondrocyte-differentiation medium for 28 days, Hybid expression was significantly up-regulated, together with the enhanced expression of hypertrophic chondrocyte markers, that is, Col10a1 and Mmp-13 (Figure 6C).

\section{Hybid Deficiency Leads to Accumulation of High-Molecular-Weight HA in the Hypertrophic Zone}

Like human HYBID, murine Hybid is a key molecule in HA depolymerization. ${ }^{8}$ Thus, we examined the link between Hybid-mediated HA depolymerization and lengthening of hypertrophic zone in $\mathrm{Hybid}^{-1-}$ mice. Histochemistry analysis showed strong staining of HA-binding protein, which 
A

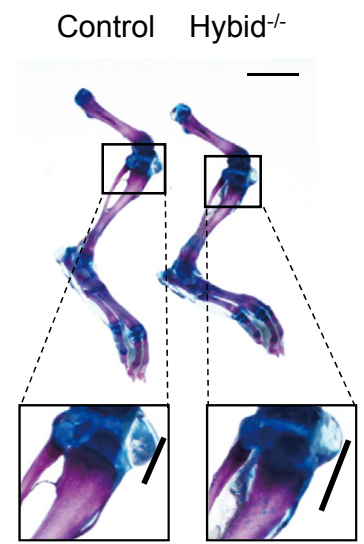

B

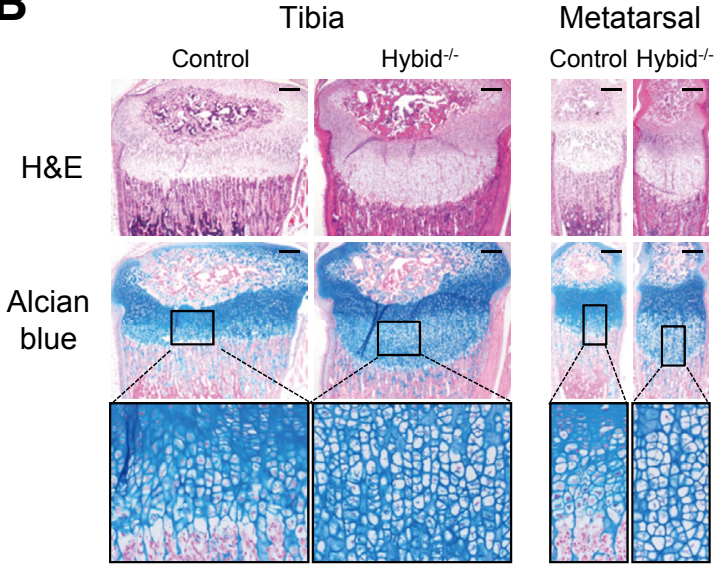

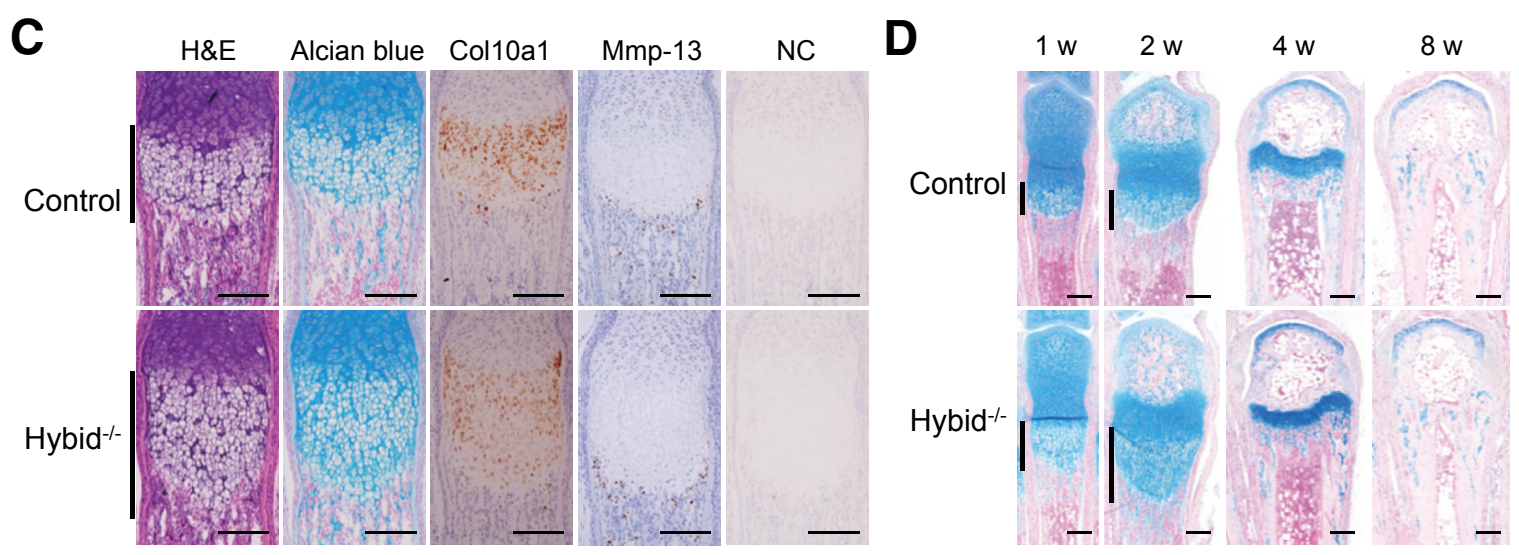

$\mathbf{E}$

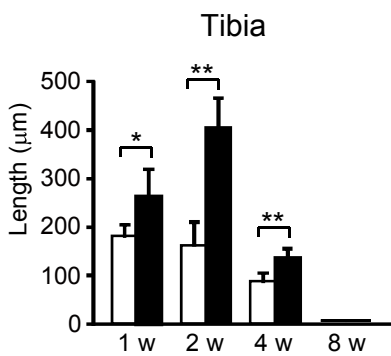

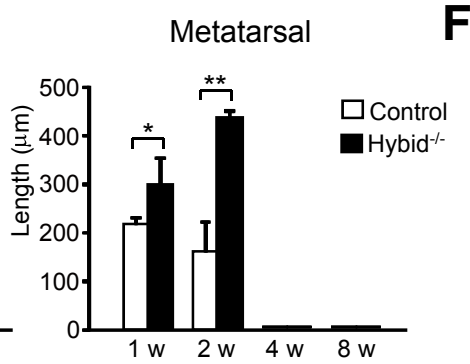

$\mathbf{F}$

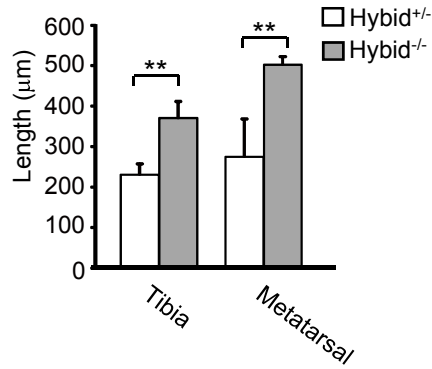

Figure $3 \mathrm{Hybid}^{-/-}$mice exhibit lengthened hypertrophic chondrocyte zone of the growth plate during development. A: Lower limbs of the 2-week-old Hybid $^{-/-}$and control mice stained with Alcian Blue (AB) (cartilage) and Alizarin Red (bone). Boxed areas are shown in the bottom panels at higher magnification. Note that the $A B$-positive cartilage tissue in the growth plate is elongated in the Hybid ${ }^{-1-}$ tibia (lines). B: Hematoxylin and eosin (H\&E) and $A B$ staining of sections from representative metatarsal and tibia in the 2-week-old $\mathrm{Hybid}^{-1-}$ and control mice. Boxed areas correspond to the high-power view of the $A B$ staining in the bottom panels. C: Representative images of H\&E and AB staining and in situ hybridization with probes to $\alpha_{1}$ type $\mathrm{X}$ collagen (Col10a1), matrix metalloprotein (Mmp)-13, or negative control (NC) in 1-week-old Hybid ${ }^{-1-}$ and control metatarsals. Lines indicate the hypertrophic zone of the growth plate. D: Representative images of $A B$ staining of metatarsals from the $\mathrm{Hybid}^{-1-}$ and control mice at 1,2,4, and 8 weeks of age. Lines indicate the hypertrophic zone of the growth plate. E: Comparison of the hypertrophic zone lengths of the tibia and metatarsal between the Hybid ${ }^{-1-}$ and control mice at $1,2,4$, and 8 weeks of age. F: Comparison of the hypertrophic zone lengths of the tibia and metatarsal between the 2-week-old $\mathrm{Hybid}^{-1-}$ and $\mathrm{Hybid}^{+/-}$littermates. Data are expressed as means $\pm \mathrm{SD} . n=3$ to $4\left(\mathbf{E}\right.$, Hybid $\left.^{-/-}\right) ; n=4\left(\mathbf{E}\right.$, control); $n=3\left(\mathbf{F}\right.$, Hybid $\left.^{+/-}\right) ; n=6\left(\mathbf{F}\right.$, Hybid $\left.^{-/-}\right) .{ }^{*} P<0.05,{ }^{* *} P<0.01$. Scale bars: $0.5 \mathrm{~cm}(\mathbf{A}) ; 200 \mu \mathrm{m}(\mathbf{B}-\mathbf{D})$.

disappeared after treatment with Streptomyces hyaluronidase, in the hypertrophic zones in both $\mathrm{Hybid}^{-1-}$ and control mice, indicating accumulation of $\mathrm{HA}$ in the hypertrophic zone in the growth plates (Figure 7A). When
HA extracted from the cartilage tissues in the epiphysis of $\mathrm{Hybid}^{-1-}$ and control mice was biochemically measured, amounts of HA were significantly higher in the $\mathrm{Hybid}^{-1-}$ mice than in the control mice at 1 and/or 2 weeks of age 

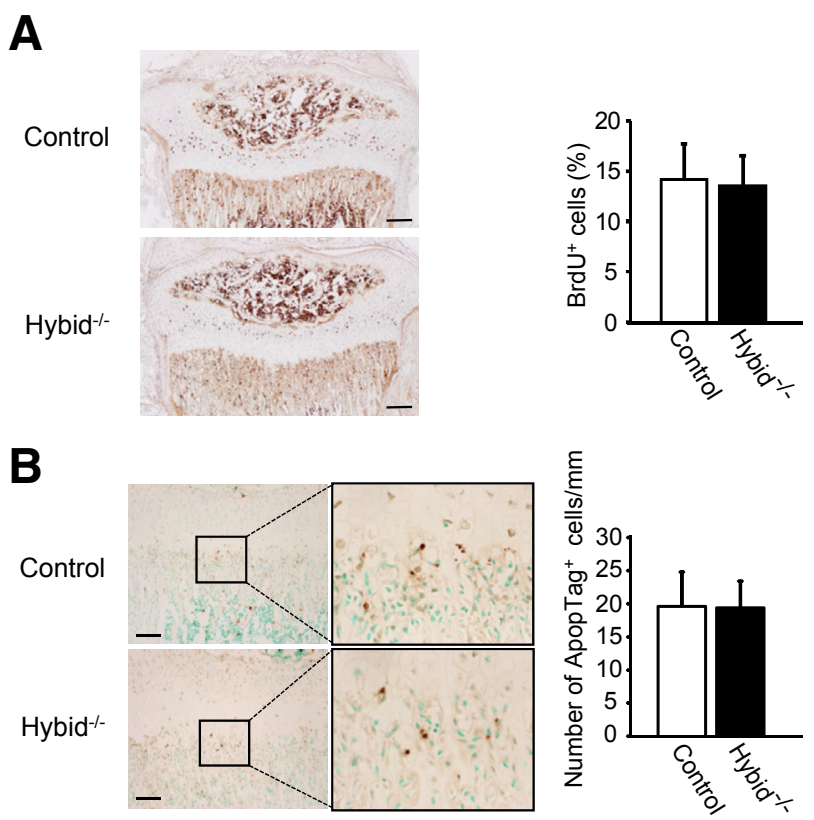

Figure 4 Assessment of chondrocyte proliferation and apoptosis in the growth plate. A: Images and quantification of chondrocyte proliferation in the proliferating zone in 3-week-old Hybid $^{-1-}$ and control mice. Representative $5^{\prime}$-bromo-2' $2^{\prime}$-deoxyuridine (BrdU)-stained sections are shown in the left panels. Quantification of the BrdU-positive chondrocytes to total chondrocytes is shown in the right panel. B: Images and quantification of apoptotic chondrocytes at the chondroosseous junction from 3-week-old $\mathrm{Hybid}^{-/-}$and control mice. Representative sections stained with ApopTag (Chemicon International, Billerica, MA) are shown in the left panel, with boxed regions corresponding to the images shown at higher magnification to the right. Numbers of the ApopTag-positive chondrocytes (in cells $/ \mathrm{mm}$ ) along the chondroosseous junction are shown in the right panel. Data are expressed as means \pm SD. $n=5$ per group. Scale bars: $200 \mu \mathrm{m}(\mathbf{A}) ; 100 \mu \mathrm{m}$ (B).

(Figure 7B). However, there were no changes in the mRNA expression levels of Hasl or -2 between the $\mathrm{Hybid}^{-/-}$and the control mice (Figure 7C). By size-exclusion chromatography, the peak HA molecular weight in the $\mathrm{Hybid}^{-/-}$ epiphysis cartilage samples was $980 \mathrm{kDa}$, whereas it was $380 \mathrm{kDa}$ in the control samples (Figure 7D). The percentage of low-molecular-weight HA (fractions 29 to 40 containing $\mathrm{HA}$ of $<380 \mathrm{kDa}$ ) in total HA was significantly lower in the samples extracted from the $\mathrm{Hybid}^{-1-}$ epiphysis cartilage, whereas the percentage of high-molecular-weight HA (fractions 25, 26, and 27 containing HA of 980 to 6400 $\mathrm{kDa}$ ) tended to be higher compared with that in the control samples (Figure 7E). These data suggest that the accumulation of high-molecular-weight HA as well as the decrease in low-molecular-weight HA in the $\mathrm{Hybid}^{-1-}$ epiphysis is possibly caused by impaired HA depolymerization.

\section{High-Molecular-Weight HA Reduces Endothelial Cell Growth and Tube Formation}

We investigated the effects of HA species of different molecular weights on growth and tube formation in endothelial cells in the presence or absence of VEGF. High-molecular-weight HA of $2700 \mathrm{kDa}$ significantly inhibited endothelial cell proliferation in the presence or absence of VEGF (Figure 8A). On the other hand, lowmolecular-weight $\mathrm{HA}$ of $2.4-\mathrm{kDa} \mathrm{HA}$ synergistically increased VEGF-induced cell proliferation, although no influence was seen on VEGF-nontreated cells (Figure 8A). Tube formation was also suppressed in the presence of high-molecular-weight $\mathrm{HA}$ of $2700 \mathrm{kDa}$ under the basal and VEGF-stimulated conditions, although lowmolecular-weight $\mathrm{HA}$ of $2.4 \mathrm{kDa}$ had no effect (Figure 8B). These results suggest that high-molecularweight HA has inhibitory effects on angiogenesis and that low-molecular-weight HA can enhance proliferation of endothelial cells.

\section{Discussion}

Here we have demonstrated, for the first time to the best of our knowledge, that targeted disruption of the Hybid gene in mice results in lengthening of the growth plate after birth, leading to shorter long bones. Our studies have provided evidence suggesting that the accumulation of high-molecular-weight HA due to HYBID deficiency causes suppression of angiogenesis and osteoclast recruitment at the chondroosseous junction in the growth plate. We have shown that high-molecular-weight HA reduces cell growth and tube formation in vascular endothelial cells under stimulation with VEGF. The data from our study illustrate the pivotal role of HYBID-mediated HA catabolism in endochondral ossification during development.

Our findings that the Hybid gene expression in 1-weekold control mice was high in the bone containing growth plates and the brain but negligible in the liver are in contrast to the tissue distributions of HYAL1 and -2 expression detected in various tissues, showing the highest expression in the liver and no or negligible expression in the brain in both mice and humans. ${ }^{20,39}$ The expression of the human CEMIP gene (alias HYBID/KIAA1199) is observed (although information in the bone is unavailable), in many organs, including the brain, skin, lung, testis, and ovary, but is notably absent in the liver, ${ }^{22}$ indicating that the expression pattern is similar to that in mice. From our data on the high-level expression of the Hybid gene in the bone and brain during postnatal development, $\mathrm{Hybid}^{-1-}$ mice were expected to have phenotypes in these organs; actually, the mice had shorter long bones during development. Although no definite morphologic abnormalities were observed in the brain of the $\mathrm{Hybid}^{-/-}$mice, neurologic and behavioral analyses of the mice disclosed a disturbance in memory function (data not shown).

The longitudinal growth of the long bones is performed by endochondral ossification in the epiphyseal growth plate, which is composed of the resting, proliferative, 
A
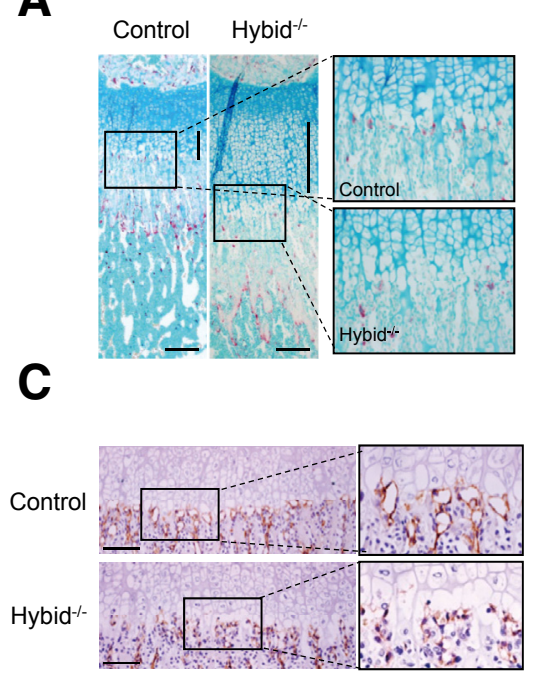
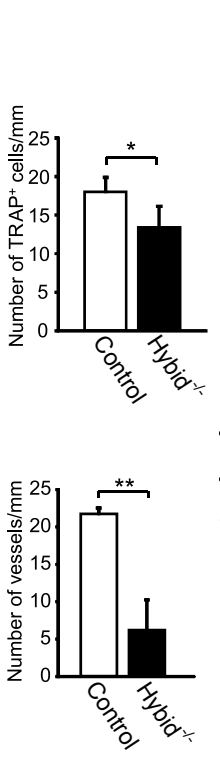

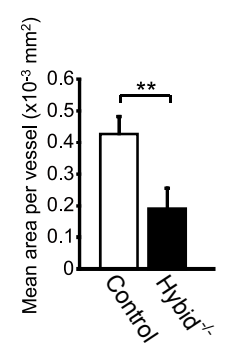

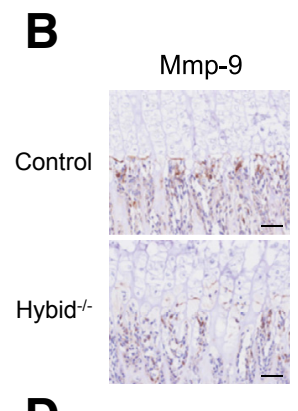

D

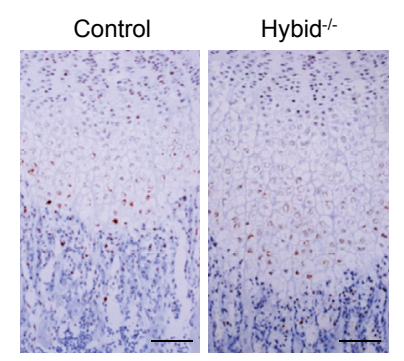

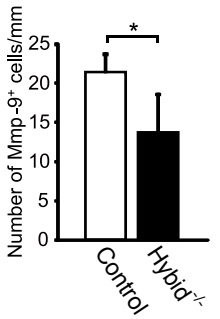

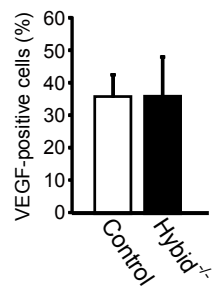

Figure $5 \mathrm{Hybid}^{-/-}$mice have fewer osteoclasts and blood vessels at the chondroosseous junction during postnatal development. A: Images and quantification of tartrate-resistant acid phosphatase (TRAP)-positive cells at the chondroosseous junction in the tibia from 2-week-old Hybid ${ }^{-/-}$and control mice. Representative TRAP-stained sections are shown in the left panel, and the boxed areas are shown at higher magnification to the right. Lines show the hypertrophic zone of the growth plate. Numbers of TRAP-positive cells along the chondroosseous junction (in cells/mm) are shown in the right panel. B: Images and quantification of matrix metalloproteinase (Mmp)-9-positive cells at the chondroosseous junction in the tibia from 2-week-old Hybid ${ }^{-1-}$ and $^{-}$ control mice. Representative Mmp-9-immunostained sections are indicated in the left panel. Numbers of Mmp-9-positive cells along the chondroosseous junction (cells $/ \mathrm{mm}$ ) are shown in the right panel. C: Images and quantification of CD31-positive vessels at the chondroosseous junction in the tibia from the 1-week-old Hybid ${ }^{-1-}$ and control mice. Representative CD31-immunostained sections are shown in the left panel and the boxed areas are magnified to the right. Quantification of number and mean luminal area of CD31-positive vessels along the chondroosseous junction is shown in the right panel. D: Images and quantification of in situ hybridization for vascular endothelial growth factor (VEGF) mRNA in sections of the tibia from the 1-week-old Hybid ${ }^{-/-}$and control mice. Representative VEGF-stained sections are shown in the left panel. Quantification of the percentages of VEGF-positive chondrocytes in the terminally differentiated hypertrophic zone is shown in the right panel. Data are expressed as means \pm SD. $n=3\left(\mathbf{A}\right.$ and $\left.\mathbf{B}, \mathrm{Hybid}^{-/}\right) ; n=4\left(\mathbf{A}\right.$ and $\mathbf{B}, \mathrm{control}^{-} \mathbf{C}$ and D, per group). ${ }^{*} P<0.05,{ }^{*} P<0.01$. Scale bars: $200 \mu \mathrm{m}$ (A); $50 \mu \mathrm{m}$ (B); $100 \mu \mathrm{m}$ (C and D).

hypertrophic, calcification, and ossification zones. ${ }^{10}$ Endochondral ossification is tightly controlled by several processes, including chondrocyte proliferation, differentiation, and apoptosis; cartilage ECM calcification and resorption by osteoclasts; vascular invasion; and bone formation. ${ }^{40,41}$ Impairment of even one of these complex processes could bring abnormal endochondral ossification. In the present study, the $\mathrm{Hybid}^{-/-}$mice exhibited lengthening of the hypertrophic zone by accumulation of hypertrophic chondrocytes. The lengthening was associated with neither deformity of the growth plates nor defects in chondrocyte proliferation and apoptosis. In addition, this phenotype was transient and coupled with significant decreases in numbers of capillaries and osteoclasts at the chondroosseous junction. Together, these findings suggest that the shorter long bones, the major phenotype of the Hybid ${ }^{-1-}$ mice, are attributed to the delayed endochondral ossification by suppression of angiogenesis and osteoclast recruitment in the growth plate.

Vascularization of hypertrophic cartilage is a crucial step in the highly orchestrated process of endochondral ossification, and many gene products are involved in this step. Among them, one of the important factors in angiogenesis in the growth plates is VEGF, which is expressed by terminally differentiated hypertrophic chondrocytes, as shown in the present and previous studies. ${ }^{10}$ The key role of VEGF in the growth plate has been confirmed by the fact that removal of angiogenic stimuli by ablating VEGF from hypertrophic chondrocytes $^{11,12}$ or by blocking VEGF receptors ${ }^{13}$ results in expansion of the hypertrophic cartilage zone. VEGF is sequestered within the ECM in tissues, and proteolytic digestion of ECM components by MMP-9 (gelatinase B), but not MMP-2 (gelatinase A), is reported to release VEGF and render normal pancreatic islets angiogenic. ${ }^{42}$ In Mmp-9-deficient mice, the major phenotype is expansion of the hypertrophic chondrocyte zone due to a delay in hypertrophic chondrocyte apoptosis and vascularization in the growth plates. ${ }^{16}$ MMP-9 is suggested to be a key regulator of growth plate angiogenesis by releasing angiogenic activators such as VEGF from the hypertrophic chondrocyte zone. ${ }^{16}$ Mmp-13-deficient mice show similar expansion of hypertrophic zone in the growth plate without definite retardation of angiogenesis. ${ }^{14,43}$ Since MMP-13 preferentially digests major components of the cartilage ECM, that is, collagen types II and X and aggrecan, ${ }^{44}$ diminished degradation of these ECM components is suggested to be involved in delayed endochondral ossification in Mmp-13-deficient mice, although the molecular mechanisms are not fully 


\section{A}

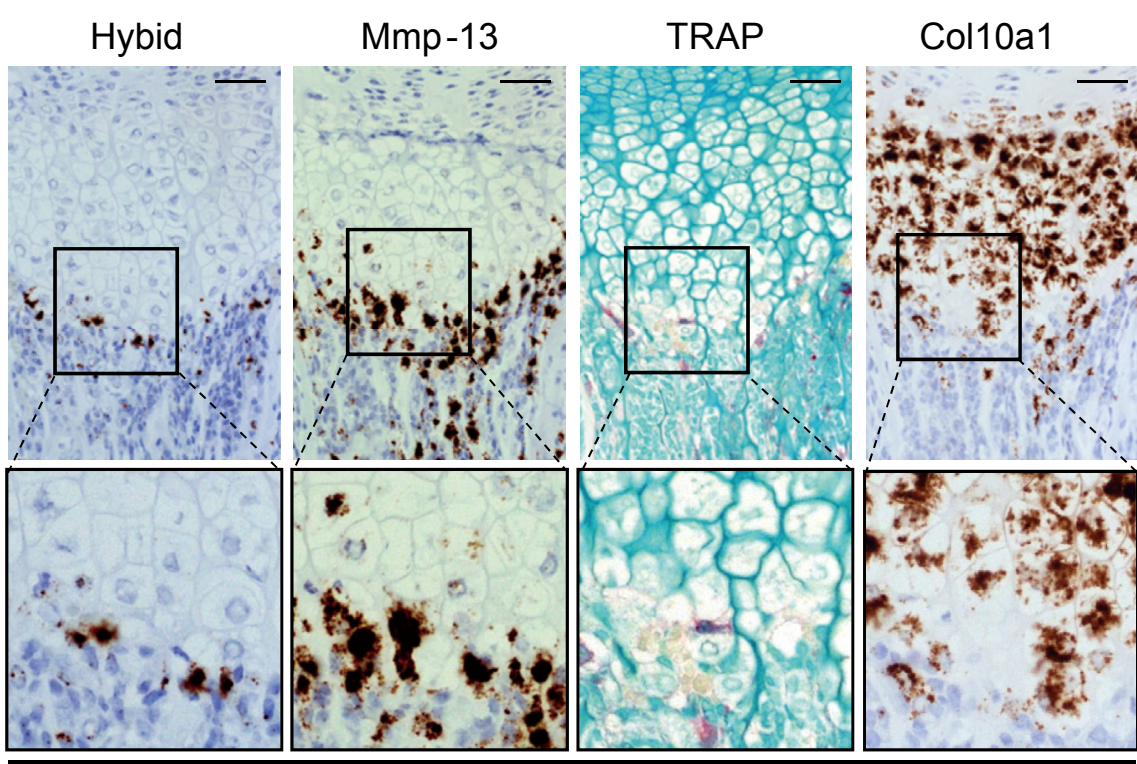

Control

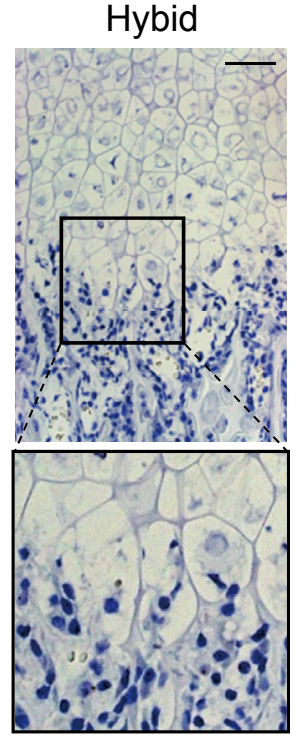

Hybid $^{-/-}$
B

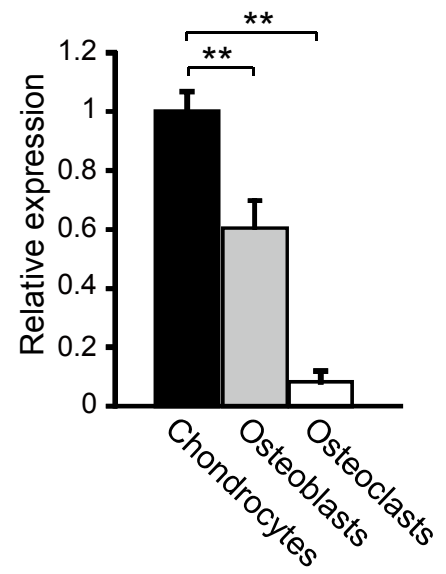

C

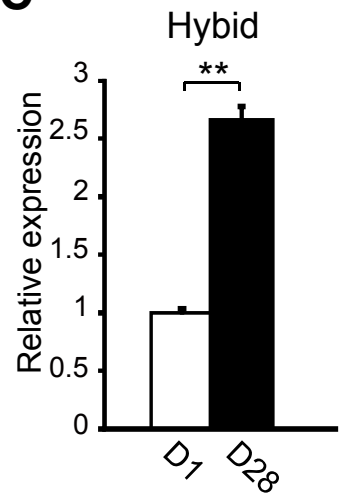

Col10a1

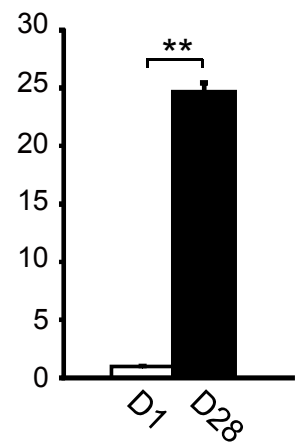

Mmp-13

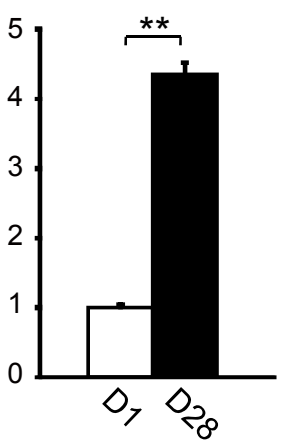

Figure 6 Terminally differentiated chondrocytes express HYBID. A: Representative images of in situ hybridization for Hybid, matrix metalloproteinase (Mmp)-13, and $\alpha_{1}$ type X collagen (Col10a1) mRNA and tartrate-resistant acid phosphatase (TRAP) staining in the growth plate of the tibia from the 1-weekold control mice. The boxed areas are shown at higher magnification in the bottom row. As in the controls, the tibia from the age-matched Hybid ${ }^{-/-}$mouse was used for in situ hybridization for Hybid. B: Relative expression of Hybid in primary control chondrocytes, osteoblasts, or osteoclasts. C: Relative expression of Hybid, Col10a1, and Mmp-13 in primary control chondrocytes under culture in the chondrocyte differentiation medium for 1 day (D1) or 28 days (D28). Data are expressed as means \pm SD. $n=3 .{ }^{* *} P<0.01$. Scale bars $=50 \mu \mathrm{m}$.

clear. $^{14,43}$ Our in situ hybridization or immunostaining showed that $\mathrm{Hybid}^{-1-}$ mice exhibited no definite changes in the expression of Vegf, Mmp-9, or Mmp-13 by the hypertrophic chondrocytes. Thus, the MMP-9-mediated VEGF pathway is unlikely to be involved in the expansion of the hypertrophic zone in the $\mathrm{Hybid}^{-/-}$mice. On the other hand, it is of note that, like Mmp-13, Hybid expression was localized to hypertrophic chondrocytes at the chondroosseous junction, which includes a thin layer of cartilage matrix separating the hypertrophic chondrocytes from invading capillaries. This layer is called the last transverse septum ${ }^{45}$ and known as an active site of ECM remodeling by MMP-13. ${ }^{14}$ Since advance degradation of proteoglycans, including aggrecan, is essential for cleavages of collagens by collagenolytic MMPs such as MMP-13, ${ }^{46-48}$ HYBID and MMP-13 may synergize to degrade the complex ECM network structures of HA, aggrecan, and collagens at the last transverse septum in the growth plates.

One of the intriguing findings in the present study is that the total amount and molecular weight of HA extracted from 


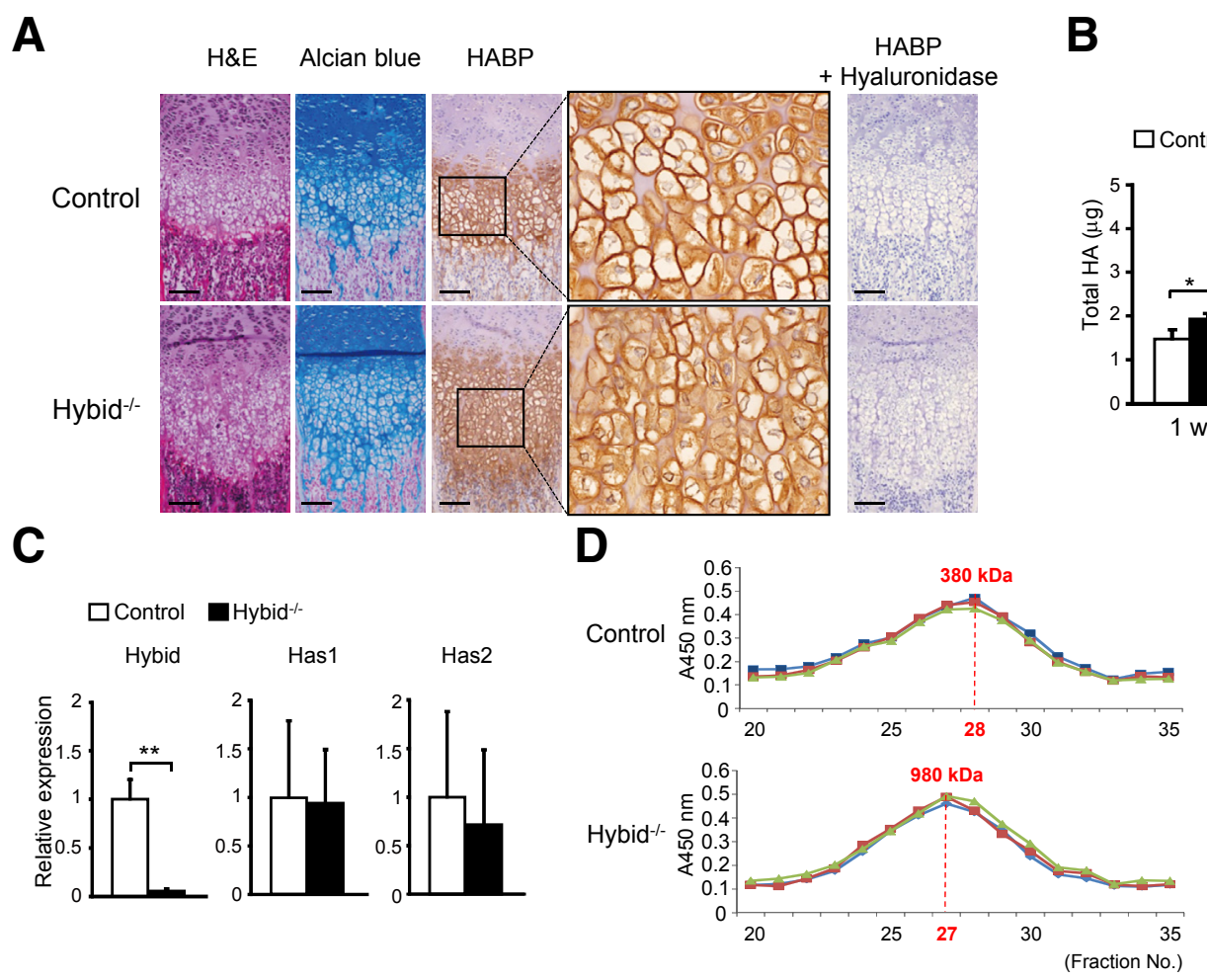

$\mathbf{D}$
$\mathbf{E}$

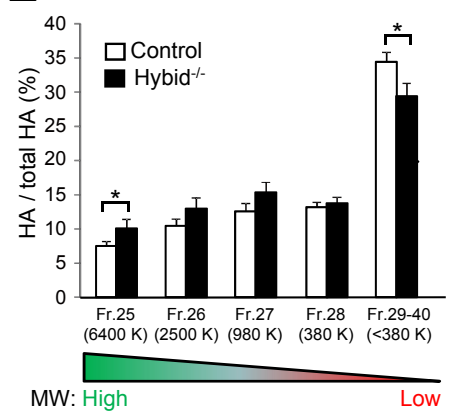

Figure 7 Hybid deficiency leads to accumulated high-molecular-weight (MW) hyaluronan (HA) in the hypertrophic zone. A: Hematoxylin and eosin (H\&E), Alcian Blue, or HA-binding protein (HABP) staining of the tibia from the 1-week-old Hybid ${ }^{-1}$ or control mice. The boxed areas of HABP-stained sections are shown at higher magnification to the right. Sections stained with HABP after treatment with hyaluronidase are also shown. B: Total amount of HA per growth plate and HA amount per dry tissue weight extracted from the epiphysis of the 1- or 2-week-old Hybid ${ }^{-1-}$ and control mice. C: Relative expression of Hybid, Has1, or Has2 in the epiphysis cartilage tissues of the 2-week-old Hybid ${ }^{-1-}$ and control mice. D: Determination of HA size distributions in the Hybid ${ }^{-1-}$ or control epiphysis cartilage tissues by size-exclusion chromatography. Colored lines (blue, red, and green) indicate three replicated chromatography analyses of extracted HA. Note that peak HA MW in the $\mathrm{Hybid}^{-/-}$epiphysis cartilage sample is $980 \mathrm{kDa}$ [fraction (fr.) 27], whereas it is $380 \mathrm{kDa}$ (fr. 28) in the control sample. E: Percentages of HA of different MWs (fr. 25, 26, 27, or 29 to 40) in total HA in the Hybid $^{-/}$or control epiphysis cartilage tissues. Data are expressed as means $\pm \mathrm{SD}$. HA (HMW) $n=4$ per group (B and C); $n=3$ per group (D). ${ }^{*} P<0.05,{ }^{*} P<0.01$. Scale bars $=100 \mu \mathrm{m}$.

the tibial growth plates were significantly higher in the Hybid $^{-1-}$ mice than in the control wild-type mice. Since the expression levels of the Has1 and Has2 were not different between the two groups, the accumulation of high-molecular-weight HA in the growth plates of the Hybid $^{-/-}$mice is ascribed to decreased HA degradation owing mainly to disruption of the Hybid gene. Biological functions of HA are known to depend on molecular size. ${ }^{49}$
A

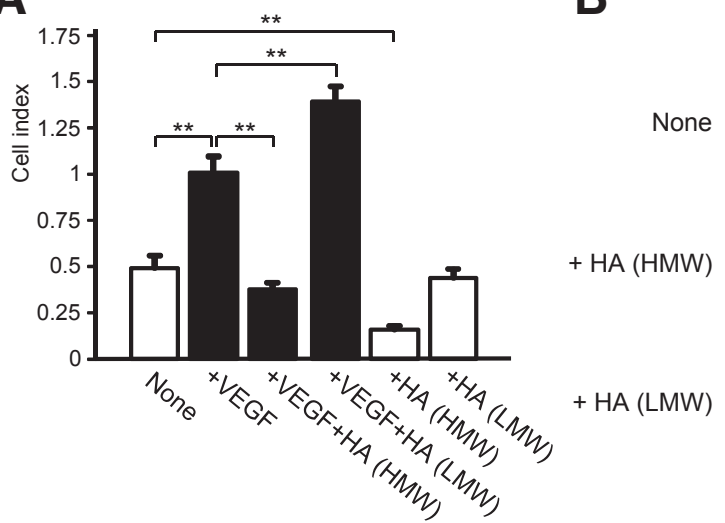

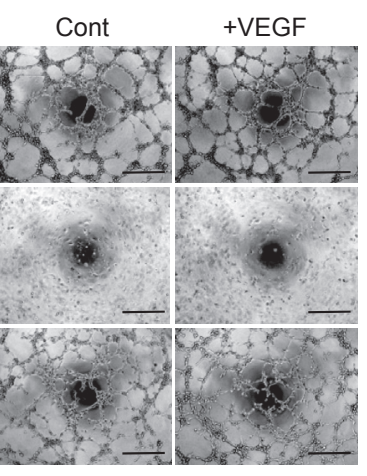

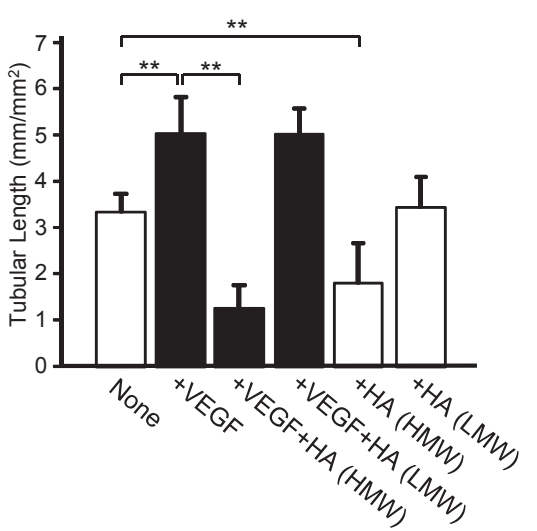

Figure 8 High-molecular-weight hyaluronan (HA) reduces endothelial cell growth and tube formation. A: Effects of high-molecular-weight (2700-kDa) or low-molecular-weight (2.4-kDa) HA on human umbilical endothelial cell (HUVEC) growth in the presence or absence of vascular endothelial growth factor (VEGF). Cell index was evaluated by the xCELLigence system (Acea Biosciences, San Diego, CA). B: Effects of high-molecular-weight (2700-kDa) or lowmolecular-weight (2.4-kDa) HA on HUVEC tube formation in the presence or absence of VEGF. Representative micrographs of tube formation are shown in the left panel. In the right panel, the tubular length (in $\mathrm{mm} / \mathrm{mm}^{2}$ ) was measured in five different areas using ImageJ, as described in Materials and Methods. Data are expressed as means \pm SD. $n=3 .{ }^{* *} P<0.01$. Scale bars $=500 \mu \mathrm{m}$. Cont, control; HMW, high-molecular-weight; LMW, low-moelcular-weight. 


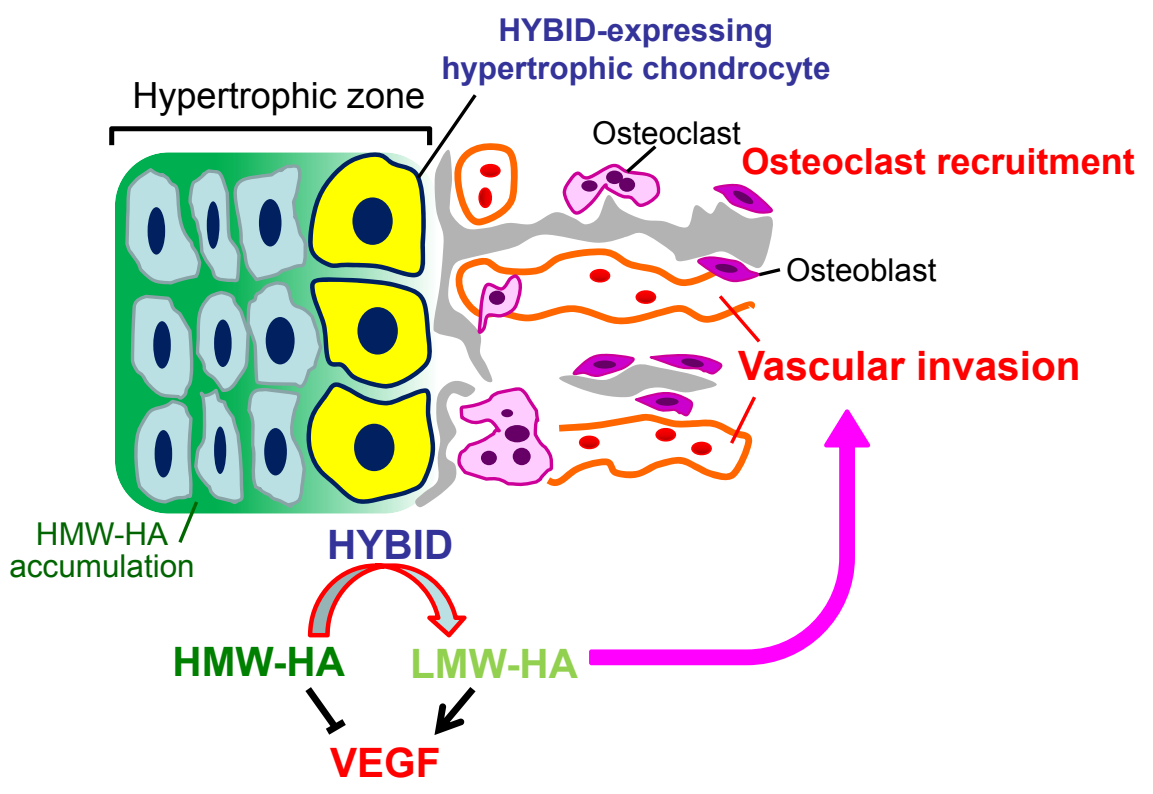

Figure 9 Schematic presentation of the functional role of HYBID in the endochondral ossification. HYBID is expressed by terminally differentiated hypertrophic chondrocytes at the chondroosseous junction and depolymerizes hyaluronan (HA) at the last transverse septum. In Hybid $^{-1-}$ mice, accumulation of high-molecularweight (HMW) HA in the hypertrophic zone may suppress vascular endothelial growth factor (VEGF)-induced angiogenesis and recruitment of osteoclasts at the chondroosseous junction, leading to delayed endochondral ossification. LMW, low-molecular-weight.

\section{Last transverse septum}

Smaller-size HA exaggerates inflammatory reactions by promoting angiogenesis ${ }^{3}$ and cell migration. On the other hand, high-molecular-weight HA is suggested to suppress angiogenesis, ${ }^{3}$ although no direct experimental evidence has been provided. Here we examined the effects of HA species on angiogenesis using vascular endothelial cells, and obtained data suggesting that high-molecular-weight HA inhibits both cell growth and tube formation in the VEGF-stimulated endothelial cells, whereas low-molecularweight HA promotes cell proliferation. Concerning the impact of HA species on osteoclastogenesis, findings from a previous study indicated that high-molecular-weight HA inhibits osteoclast differentiation of monocyte/macrophage lineage cells through Toll-like receptor 4 by interfering with macrophage colony-stimulating factor signaling. ${ }^{50}$ With these findings taken together, we hypothesize that highmolecular-weight HA accumulated in the hypertrophic chondrocyte zone of the growth plates contributes to delayed endochondral ossification in $\mathrm{Hybid}^{-1-}$ mice through suppression of VEGF-induced angiogenesis and osteoclastogenesis at the chondroosseous junction (Figure 9).

HYBID is overexpressed by pathologic human tissues and/or cells in several diseases, including arthritides, ${ }^{5}$ cancers, ${ }^{22,23}$ and Werner syndrome. ${ }^{22}$ In addition, mutations in the human HYBID gene, most of which are loss-of-function mutations, ${ }^{5}$ have been reportedly related to nonsyndromic hearing loss. ${ }^{7}$ Although pathologic roles of HYBID in most of these diseases, even its relation to HA depolymerization, remain elusive, we have provided evidence that HYBID expressed by synovial fibroblasts from osteoarthritis or rheumatoid arthritis is implicated in depolymerization of high-molecular-weight HA into smaller-size fragments. ${ }^{5}$ Since HYBID-mediated depolymerization of high-molecular-weight $\mathrm{HA}$ is performed in the clathrin-coated vesicles and lowermolecular-weight fragments are secreted extracellularly, this process by synovial fibroblasts seems to be involved in the accumulation of the HA fragments in joint fluids in these diseases. ${ }^{51}$ In osteoarthritic cartilage, chondrocytes commonly express hypertrophic chondrocyte markers such as VEGF and COL10A1, resembling the chondrocyte phenotype observed in the hypertrophic zone of the metaphyseal growth plates. ${ }^{52}$ The findings from our preliminary study show that osteoarthritis chondrocytes in the articular cartilage overexpress HYBID, suggesting an involvement of HYBID in HA degradation during osteoarthritic cartilage destruction (data not shown). Studies using human tissues are important for exploring the implications of HYBID in human diseases, but animal models are essential for analyzing the detailed molecular mechanisms of HYBID under pathologic conditions. Since Hybid ${ }^{-1-}$ mice exhibit transient phenotype in bone growth but no abnormalities in the structures of whole organs including articular cartilage, they are considered to be suitable for the analyses of HYBID functions under pathologic conditions such as experimental arthritides and cancers.

\section{Acknowledgments}

We thank Aya Shiraishi and Haruko Inomata in our laboratory for technical assistance, and Mika Aoki and Aya Nagaoka (Kao Corporation) for their assistance in the analyses of HA molecular weight distribution and Hybid-deficient mice. HA species were gifts from Chugai Pharmaceutical Co., Ltd. 


\section{References}

1. Underhill CB, Toole BP: Binding of hyaluronate to the surface of cultured cells. J Cell Biol 1979, 82:475-484

2. Maytin EV: Hyaluronan: more than just a wrinkle filler. Glycobiology 2016, 26:553-559

3. Monslow J, Govindaraju P, Pure E: Hyaluronan - a functional and structural sweet spot in the tissue microenvironment. Front Immunol $2015,6: 231$

4. Triggs-Raine B, Natowicz MR: Biology of hyaluronan: insights from genetic disorders of hyaluronan metabolism. World J Biol Chem 2015, 6:110-120

5. Yoshida H, Nagaoka A, Kusaka-Kikushima A, Tobiishi M, Kawabata K, Sayo T, Sakai S, Sugiyama Y, Enomoto H, Okada Y, Inoue S: KIAA1199, a deafness gene of unknown function, is a new hyaluronan binding protein involved in hyaluronan depolymerization. Proc Natl Acad Sci U S A 2013, 110:5612-5617

6. Nagaoka A, Yoshida H, Nakamura S, Morikawa T, Kawabata K, Kobayashi M, Sakai S, Takahashi Y, Okada Y, Inoue S: Regulation of hyaluronan (HA) metabolism mediated by HYBID (Hyaluronanbinding Protein Involved in HA Depolymerization, KIAA1199) and HA synthases in growth factor-stimulated fibroblasts. J Biol Chem 2015, 290:30910-30923

7. Abe S, Usami S, Nakamura Y: Mutations in the gene encoding KIAA1199 protein, an inner-ear protein expressed in Deiters' cells and the fibrocytes, as the cause of nonsyndromic hearing loss. J Hum Genet 2003, 48:564-570

8. Yoshida H, Nagaoka A, Nakamura S, Sugiyama Y, Okada Y, Inoue S: Murine homologue of the human KIAA1199 is implicated in hyaluronan binding and depolymerization. FEBS Open Bio 2013, 3: 352-356

9. Yoshida H, Nagaoka A, Nakamura S, Tobiishi M, Sugiyama Y, Inoue S: N-Terminal signal sequence is required for cellular trafficking and hyaluronan-depolymerization of KIAA1199. FEBS Lett 2014, 588:111-116

10. Aiken A, Khokha R: Unraveling metalloproteinase function in skeletal biology and disease using genetically altered mice. Biochim Biophys Acta 2010, 1803:121-132

11. Maes C, Carmeliet P, Moermans K, Stockmans I, Smets N, Collen D, Bouillon R, Carmeliet G: Impaired angiogenesis and endochondral bone formation in mice lacking the vascular endothelial growth factor isoforms VEGF164 and VEGF188. Mech Dev 2002, 111:61-73

12. Zelzer E, Mamluk R, Ferrara N, Johnson RS, Schipani E, Olsen BR: VEGFA is necessary for chondrocyte survival during bone development. Development 2004, 131:2161-2171

13. Gerber HP, Vu TH, Ryan AM, Kowalski J, Werb Z, Ferrara N: VEGF couples hypertrophic cartilage remodeling, ossification and angiogenesis during endochondral bone formation. Nat Med 1999, 5:623-628

14. Stickens D, Behonick DJ, Ortega N, Heyer B, Hartenstein B, Yu Y, Fosang AJ, Schorpp-Kistner M, Angel P, Werb Z: Altered endochondral bone development in matrix metalloproteinase 13-deficient mice. Development 2004, 131:5883-5895

15. Takaishi H, Kimura T, Dalal S, Okada Y, D'Armiento J: Joint diseases and matrix metalloproteinases: a role for MMP-13. Curr Pharm Biotechnol 2008, 9:47-54

16. Vu TH, Shipley JM, Bergers G, Berger JE, Helms JA, Hanahan D, Shapiro SD, Senior RM, Werb Z: MMP-9/gelatinase B is a key regulator of growth plate angiogenesis and apoptosis of hypertrophic chondrocytes. Cell 1998, 93:411-422

17. Holmbeck K, Bianco P, Caterina J, Yamada S, Kromer M, Kuznetsov SA, Mankani M, Robey PG, Poole AR, Pidoux I, Ward JM, Birkedal-Hansen H: MT1-MMP-deficient mice develop dwarfism, osteopenia, arthritis, and connective tissue disease due to inadequate collagen turnover. Cell 1999, 99:81-92

18. Roughley PJ, Lamplugh L, Lee ER, Matsumoto K, Yamaguchi Y: The role of hyaluronan produced by Has2 gene expression in development of the spine. Spine (Phila Pa 1976) 2011, 36: E914-E920

19. Martin DC, Atmuri V, Hemming RJ, Farley J, Mort JS, Byers S, Hombach-Klonisch S, Csoka AB, Stern R, Triggs-Raine BL: A mouse model of human mucopolysaccharidosis IX exhibits osteoarthritis. Hum Mol Genet 2008, 17:1904-1915

20. Jadin L, Wu X, Ding H, Frost GI, Onclinx C, Triggs-Raine B, Flamion B: Skeletal and hematological anomalies in HYAL2deficient mice: a second type of mucopolysaccharidosis IX? FASEB J 2008, 22:4316-4326

21. Chowdhury B, Hemming R, Hombach-Klonisch S, Flamion B, Triggs-Raine B: Murine hyaluronidase 2 deficiency results in extracellular hyaluronan accumulation and severe cardiopulmonary dysfunction. J Biol Chem 2013, 288:520-528

22. Michishita E, Garces G, Barrett JC, Horikawa I: Upregulation of the KIAA1199 gene is associated with cellular mortality. Cancer Lett 2006, 239:71-77

23. Matsuzaki S, Tanaka F, Mimori K, Tahara K, Inoue H, Mori M: Clinicopathologic significance of KIAA1199 overexpression in human gastric cancer. Ann Surg Oncol 2009, 16:2042-2051

24. Tian X, Azpurua J, Hine C, Vaidya A, Myakishev-Rempel M, Ablaeva J, Mao Z, Nevo E, Gorbunova V, Seluanov A: High-molecular-mass hyaluronan mediates the cancer resistance of the naked mole rat. Nature 2013, 499:346-349

25. Sakai K, Miyazaki J: A transgenic mouse line that retains Cre recombinase activity in mature oocytes irrespective of the Cre transgene transmission. Biochem Biophys Res Commun 1997, 237: 318-324

26. Shimoda M, Principe S, Jackson HW, Luga V, Fang H, Molyneux SD, Shao YW, Aiken A, Waterhouse PD, Karamboulas C, Hess FM, Ohtsuka T, Okada Y, Ailles L, Ludwig A, Wrana JL, Kislinger T, Khokha R: Loss of the Timp gene family is sufficient for the acquisition of the CAF-like cell state. Nat Cell Biol 2014, 16 : 889-901

27. Horiuchi K, Kimura T, Miyamoto $\mathrm{T}$, Miyamoto $\mathrm{K}$, Akiyama $\mathrm{H}$, Takaishi H, Morioka H, Nakamura T, Okada Y, Blobel CP, Toyama Y: Conditional inactivation of TACE by a Sox9 promoter leads to osteoporosis and increased granulopoiesis via dysregulation of IL-17 and G-CSF. J Immunol 2009, 182:2093-2101

28. Tohmonda T, Yoda M, Iwawaki T, Matsumoto M, Nakamura M, Mikoshiba K, Toyama Y, Horiuchi K: IRE1alpha/XBP1-mediated branch of the unfolded protein response regulates osteoclastogenesis. J Clin Invest 2015, 125:3269-3279

29. Shimoda M, Hashimoto G, Mochizuki S, Ikeda E, Nagai N, Ishida S, Okada Y: Binding of ADAM28 to P-selectin glycoprotein ligand-1 enhances P-selectin-mediated leukocyte adhesion to endothelial cells. J Biol Chem 2007, 282:25864-25874

30. McLeod MJ: Differential staining of cartilage and bone in whole mouse fetuses by Alcian Blue and Alizarin Red S. Teratology 1980, 22:299-301

31. Meyer LJ, Stern R: Age-dependent changes of hyaluronan in human skin. J Invest Dermatol 1994, 102:385-389

32. Sato Y, Mukai K, Watanabe S, Goto M, Shimosato Y: The AMeX method. A simplified technique of tissue processing and paraffin embedding with improved preservation of antigens for immunostaining. Am J Pathol 1986, 125:431-435

33. Tobiishi M, Sayo T, Yoshida H, Kusaka A, Kawabata K, Sugiyama Y, Ishikawa O, Inoue S: Changes in epidermal hyaluronan metabolism following UVB irradiation. J Dermatol Sci 2011, 64: $31-38$

34. Shimoda M, Horiuchi K, Sasaki A, Tsukamoto T, Okabayashi K, Hasegawa H, Kitagawa Y, Okada Y: Epithelial cell-derived a disintegrin and metalloproteinase-17 confers resistance to colonic inflammation through EGFR activation. EBioMedicine 2016, 5:114-124

35. Arnaoutova I, Kleinman HK: In vitro angiogenesis: endothelial cell tube formation on gelled basement membrane extract. Nat Protoc 2010, 5:628-635 
36. Yatabe T, Mochizuki S, Takizawa M, Chijiiwa M, Okada A Kimura T, Fujita Y, Matsumoto H, Toyama Y, Okada Y: Hyaluronan inhibits expression of ADAMTS4 (aggrecanase-1) in human osteoarthritic chondrocytes. Ann Rheum Dis 2009, 68: $1051-1058$

37. Hashimoto G, Inoki I, Fujii Y, Aoki T, Ikeda E, Okada Y: Matrix metalloproteinases cleave connective tissue growth factor and reactivate angiogenic activity of vascular endothelial growth factor 165 . J Biol Chem 2002, 277:36288-36295

38. Lu P, Takai K, Weaver VM, Werb Z: Extracellular matrix degradation and remodeling in development and disease. Cold Spring Harb Perspect Biol 2011, 3:a005058

39. Csoka AB, Scherer SW, Stern R: Expression analysis of six paralogous human hyaluronidase genes clustered on chromosomes 3p21 and 7q31. Genomics 1999, 60:356-361

40. Karsenty G, Wagner EF: Reaching a genetic and molecular understanding of skeletal development. Dev Cell 2002, 2:389-406

41. Ortega N, Behonick DJ, Werb Z: Matrix remodeling during endochondral ossification. Trends Cell Biol 2004, 14:86-93

42. Bergers G, Brekken R, McMahon G, Vu TH, Itoh T, Tamaki K, Tanzawa K, Thorpe P, Itohara S, Werb Z, Hanahan D: Matrix metalloproteinase- 9 triggers the angiogenic switch during carcinogenesis. Nat Cell Biol 2000, 2:737-744

43. Inada $\mathrm{M}$, Wang $\mathrm{Y}$, Byrne $\mathrm{MH}$, Rahman MU, Miyaura C, Lopez-Otin C, Krane SM: Critical roles for collagenase-3 (Mmp13) in development of growth plate cartilage and in endochondral ossification. Proc Natl Acad Sci U S A 2004, 101: $17192-17197$
44. Fosang AJ, Last K, Knauper V, Murphy G, Neame PJ: Degradation of cartilage aggrecan by collagenase-3 (MMP-13). FEBS Lett 1996, 380:17-20

45. Lee ER, Murphy G, El-Alfy M, Davoli MA, Lamplugh L, Docherty AJ, Leblond CP: Active gelatinase B is identified by histozymography in the cartilage resorption sites of developing long bones. Dev Dyn 1999, 215:190-205

46. Byers S, van Rooden JC, Foster BK: Structural changes in the large proteoglycan, aggrecan, in different zones of the ovine growth plate. Calcif Tissue Int 1997, 60:71-78

47. Mwale F, Billinghurst C, Wu W, Alini M, Webber C, Reiner A, Ionescu M, Poole J, Poole AR: Selective assembly and remodelling of collagens II and IX associated with expression of the chondrocyte hypertrophic phenotype. Dev Dyn 2000, 218:648-662

48. Pratta MA, Yao W, Decicco C, Tortorella MD, Liu RQ, Copeland RA, Magolda R, Newton RC, Trzaskos JM, Arner EC: Aggrecan protects cartilage collagen from proteolytic cleavage. J Biol Chem 2003, 278:45539-45545

49. Toole BP: Hyaluronan: from extracellular glue to pericellular cue. Nat Rev Cancer 2004, 4:528-539

50. Chang EJ, Kim HJ, Ha J, Kim HJ, Ryu J, Park KH, Kim UH, Lee ZH, Kim HM, Fisher DE, Kim HH: Hyaluronan inhibits osteoclast differentiation via Toll-like receptor 4. J Cell Sci 2007, 120:166-176

51. Tamer TM: Hyaluronan and synovial joint: function, distribution and healing. Interdiscip Toxicol 2013, 6:111-125

52. van der Kraan PM, van den Berg WB: Chondrocyte hypertrophy and osteoarthritis: role in initiation and progression of cartilage degeneration? Osteoarthritis Cartilage 2012, 20:223-232 